\title{
WestVirginiaUniversity
}

THE RESEARCH REPOSITORY @ WVU

Graduate Theses, Dissertations, and Problem Reports

2001

\section{Order effects of fear and pain induction}

\author{
Kevin Erik Vowles \\ West Virginia University
}

Follow this and additional works at: https://researchrepository.wvu.edu/etd

\section{Recommended Citation}

Vowles, Kevin Erik, "Order effects of fear and pain induction" (2001). Graduate Theses, Dissertations, and Problem Reports. 804.

https://researchrepository.wvu.edu/etd/804

This Thesis is protected by copyright and/or related rights. It has been brought to you by the The Research Repository @ WVU with permission from the rights-holder(s). You are free to use this Thesis in any way that is permitted by the copyright and related rights legislation that applies to your use. For other uses you must obtain permission from the rights-holder(s) directly, unless additional rights are indicated by a Creative Commons license in the record and/ or on the work itself. This Thesis has been accepted for inclusion in WVU Graduate Theses, Dissertations, and Problem Reports collection by an authorized administrator of The Research Repository @ WVU. For more information, please contact researchrepository@mail.wvu.edu. 
Order Effects of Fear and Pain Induction

\author{
Kevin E. Vowles \\ Thesis submitted to the \\ Eberly College of Arts and Sciences \\ at West Virginia University \\ in partial fulfillment of the requirements \\ for the degree of \\ Master of Arts \\ in \\ Psychology
}
Daniel W. McNeil, Ph.D, Chair
Karl G. Hursey, Ph.D
Kevin T. Larkin, Ph.D
B. Kent Parker, Ph.D

Department of Psychology

Morgantown, West Viriginia

2001

Keywords: Pain, Fear, Emotion, Clinical Psychology, Human Participants

Copyright 2001 Kevin E. Vowles 


\section{ABSTRACT \\ Order Effects of Fear and Pain Induction}

\section{Kevin E. Vowles}

Although pain responding and emotional states such as fear are highly correlated and appear to interact, the causal relations between these variables have yet to be fully defined. This study sought to further illuminate these relations by investigating how exposure to one of these states (i.e., pain or fear) affects responding to the other. The order in which participants experienced fearful or painful stimuli was manipulated, as well as fear level (i.e., "low" \& "high"). Measures of behavioral escape, heart rate, and verbal reports were obtained throughout four experimental trials, as well as rankings of aversiveness for all stimuli encountered. Results indicated a high degree of synchrony among rankings of aversiveness and the three response modalities, with the exception of verbal reports of pain. Specifically, high fear, which was found to be the most aversive and appeared to inhibit verbal reports of pain and elevate all other measures of distress, especially when high fear was encountered first. These findings indicate that the stimulus perceived to be the most aversive (i.e., high fear) accounted for the greatest variability in responding. This pattern was replicated for the two stimuli found to be less aversive (i.e., pain and low fear, respectively). In sum, fear and pain, in and of themselves, do not dictate the nature of their relation; the important factor is how aversive they are perceived to be in relation to one another. 


\section{Acknowledgements}

First, many thanks to my thesis committee: Dr. Karl G. Hursey, Dr. Kevin T. Larkin, and Dr. B. Kent Parker. Each of these individuals provided important feedback and support to this project. Special thanks to my thesis committee chair, Dr. Daniel W. McNeil, without whom this project would never have been accomplished. Dan's support and guidance have been very valuable over the course of my graduate career. Thanks also to the Department of Psychology Alumni Fund for providing financial support of this research.

John T. Sorrell was instrumental in providing necessary support and assistance in getting this project "off the ground" and I value his guidance, assistance, and friendship. Suzanne Lawrence and Erin Rice also generously provided their time and energy to many phases of this project and I would like to thank them for their hard work and dedication.

My father, Keith Vowles, has always provided me with unconditional encouragement and love, especially during the tougher times of my life. This is the most valuable thing anyone has ever given to me. To my step-mother, Susan Vowles, the hard work and dedication that you show in your own work is an inspiration. I would also like to thank my mother, Sonya Vowles, whose spirit and love remain with me today.

Finally, thanks to my friend and companion, Janet Prather, just for being you. 


\section{Table of Contents}

\section{Title Page}

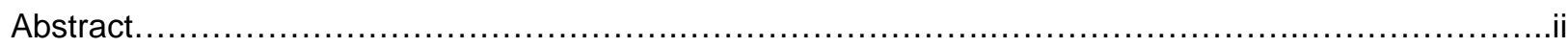

Acknowledgements......................

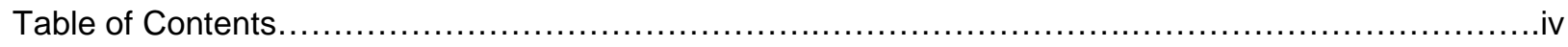

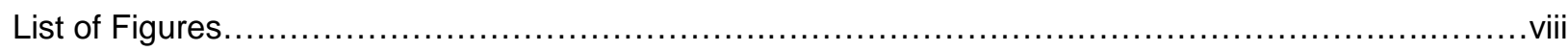

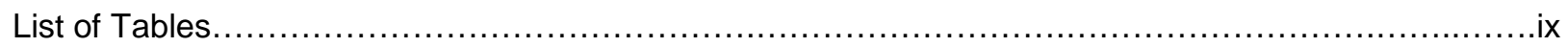

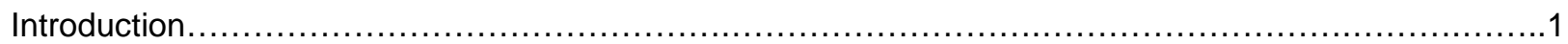

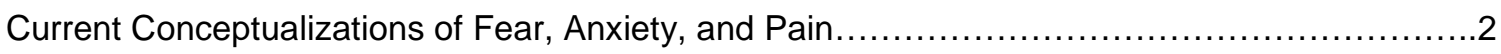

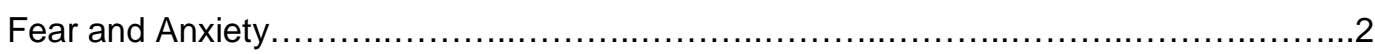

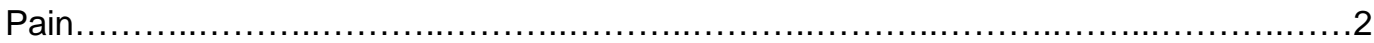

Empirical Work Regarding the Relation Between Fear and Pain...............................

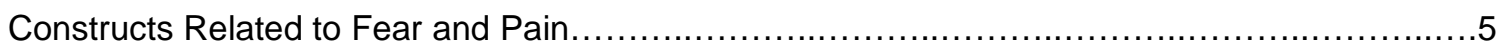

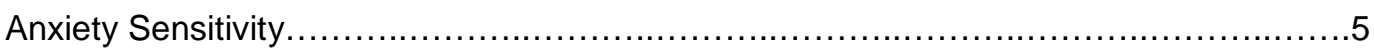

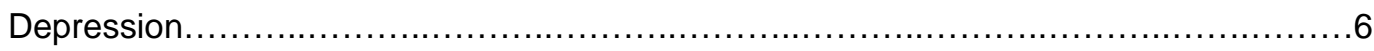

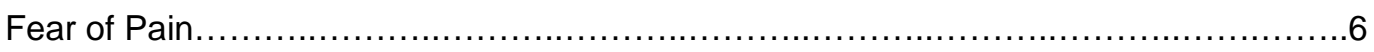

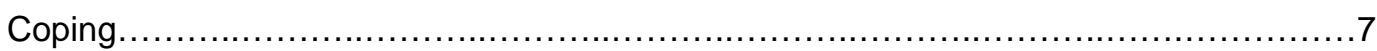

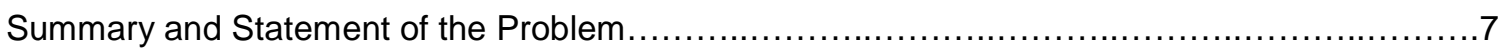

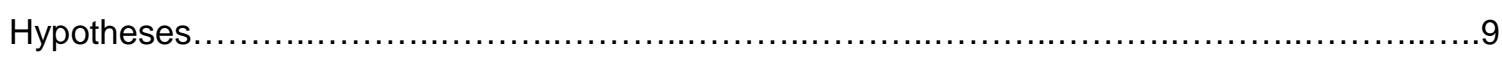

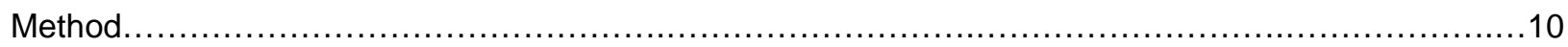

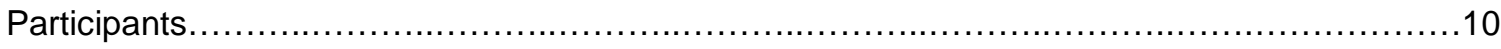

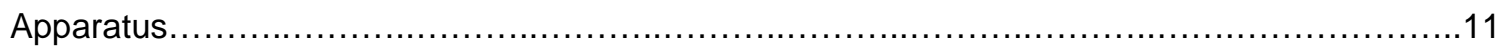

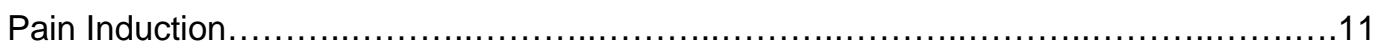

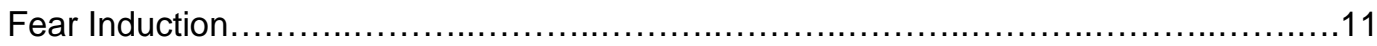

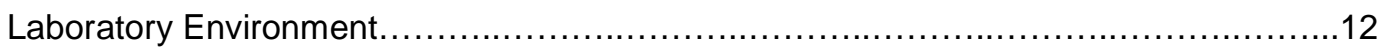

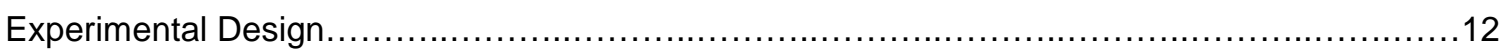

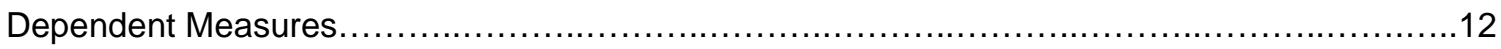




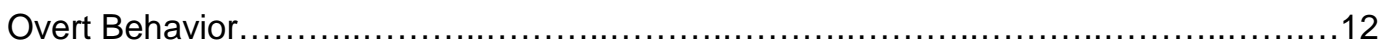

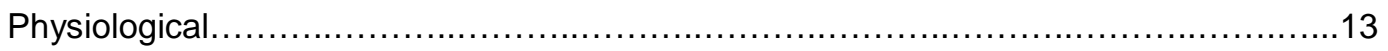

Self-Report of Emotional and Pain States........................................ 13

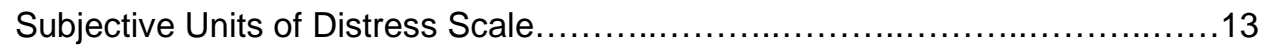

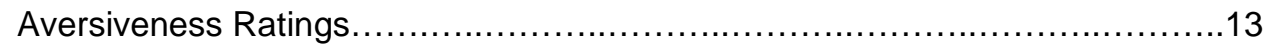

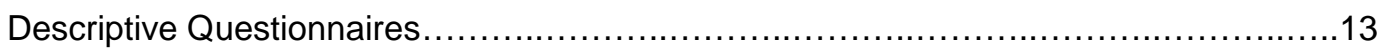

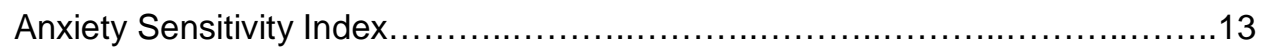

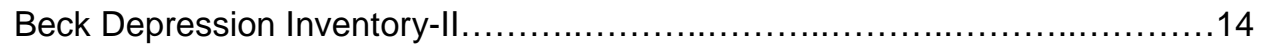

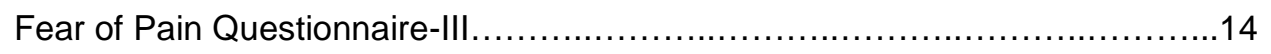

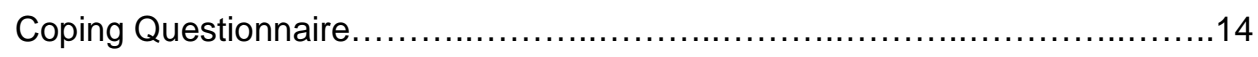

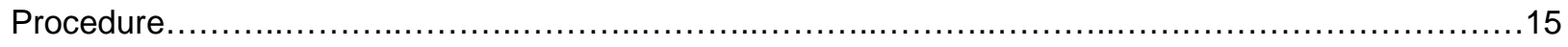

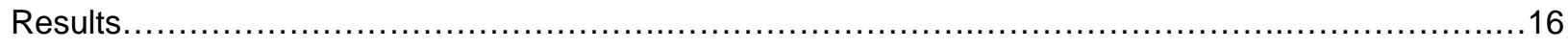

Statistical Approach and Data Reduction.............................................16

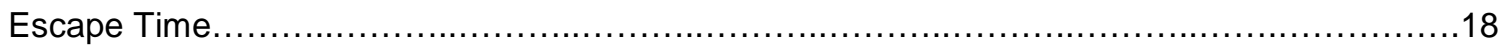

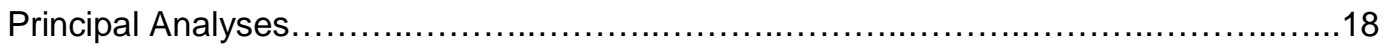

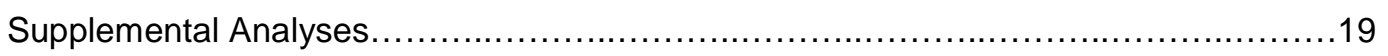

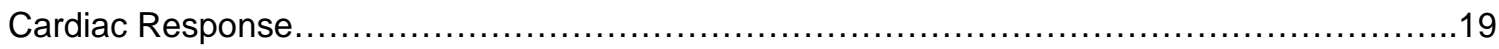

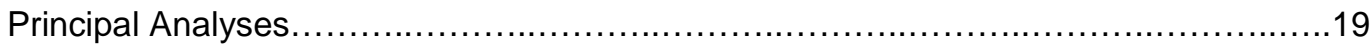

Pre-Trial Comparisons................................................ 19

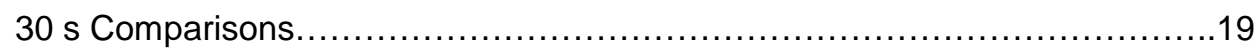

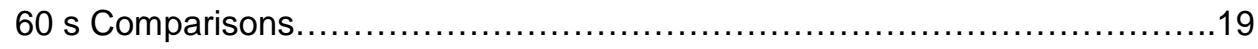

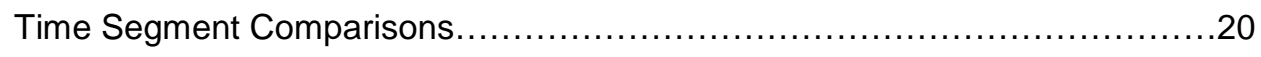

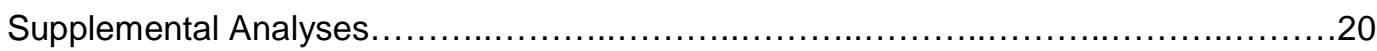

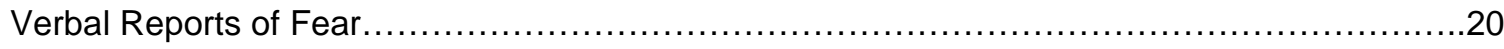

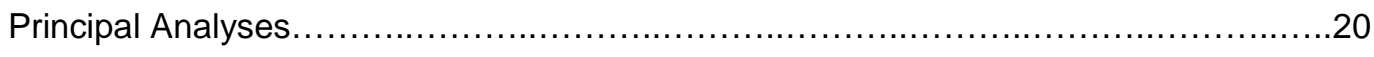

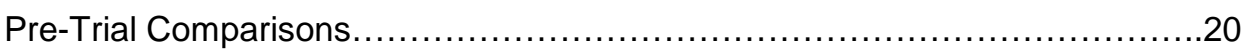

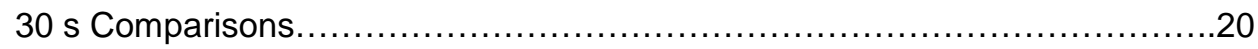




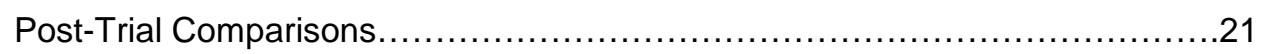

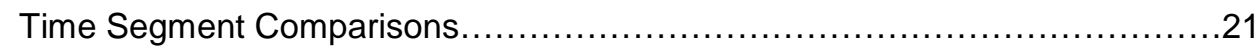

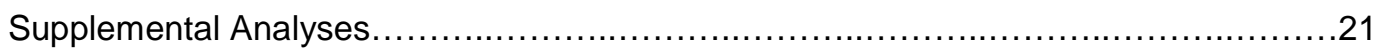

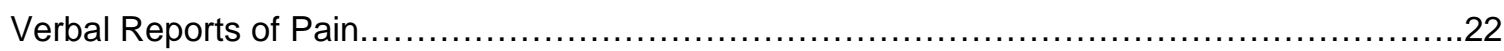

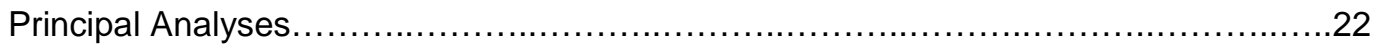

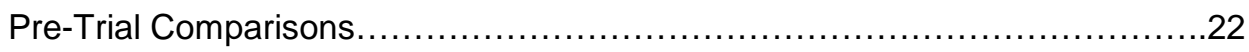

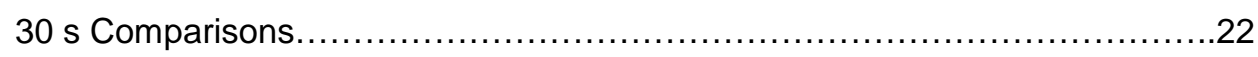

Post-Trial Comparisons....................................................22

Time Segment Comparisons...........................................22

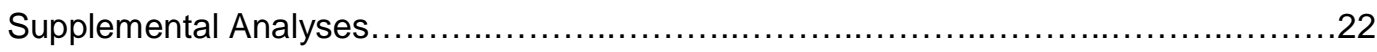

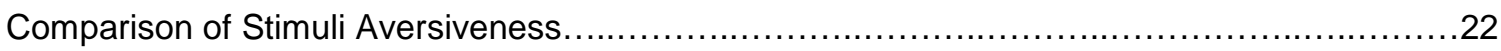

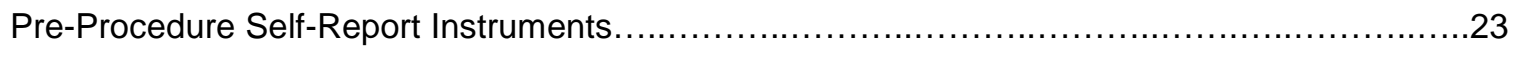

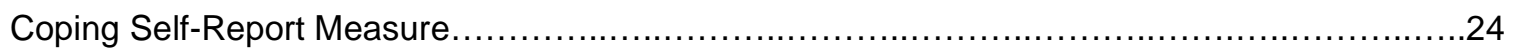

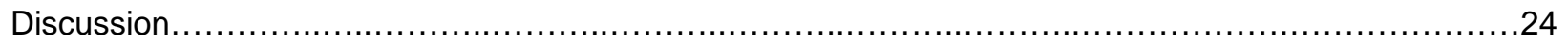

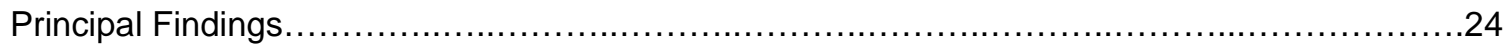

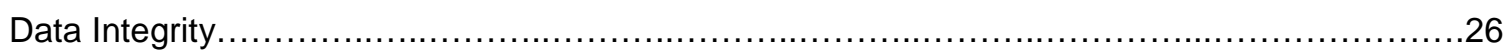

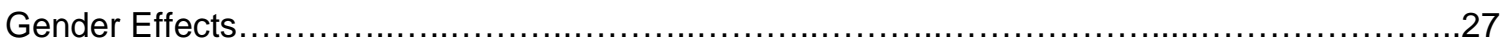

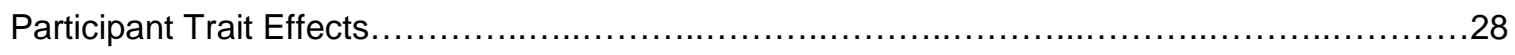

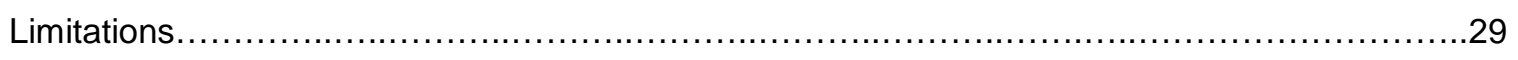

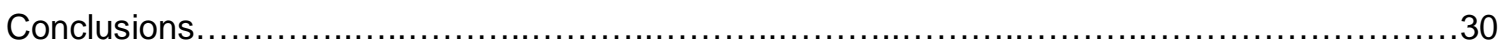

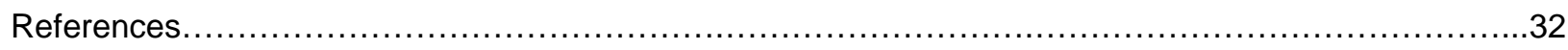

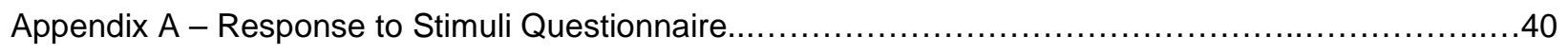

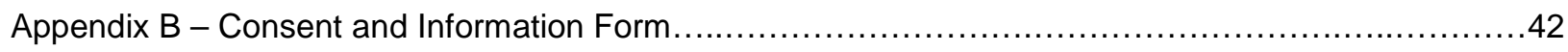

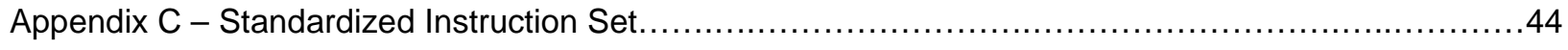

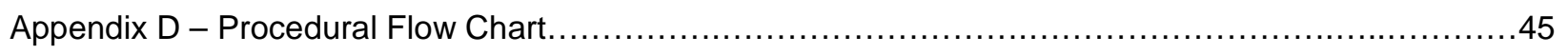

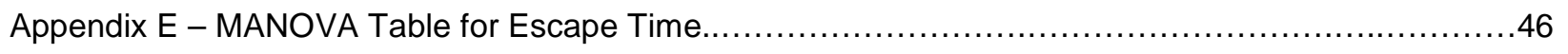

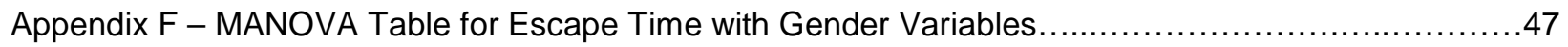




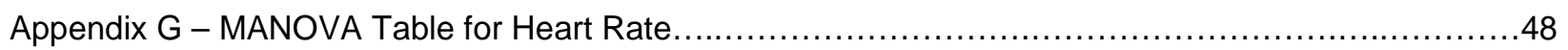

Appendix H - MANOVA Table for Heart Rate with Gender Variables...................................49

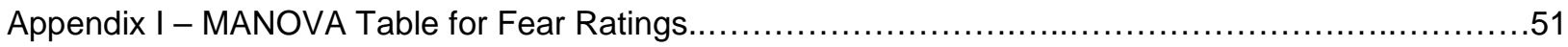

Appendix J - MANOVA Table for Fear Ratings with Gender Variables ...................................52

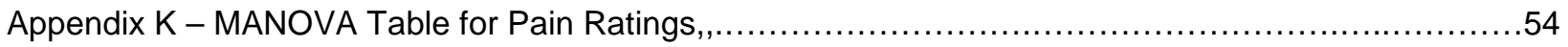

Appendix $L$ - MANOVA Table for Pain Ratings with Gender Variables...............................55

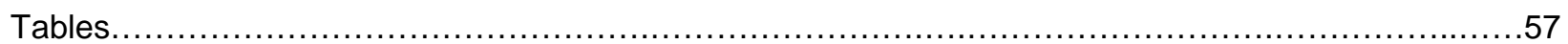

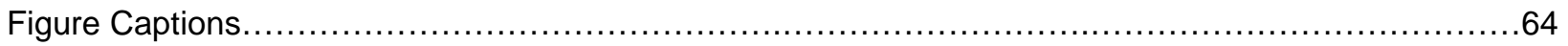

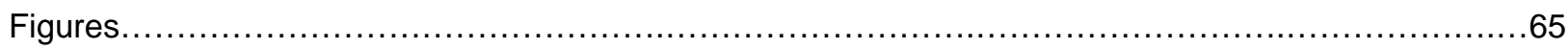

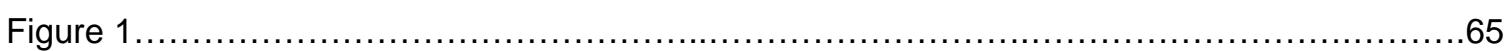

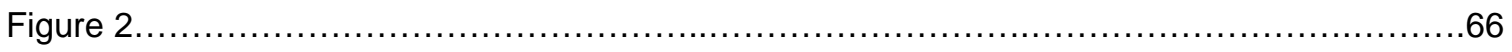

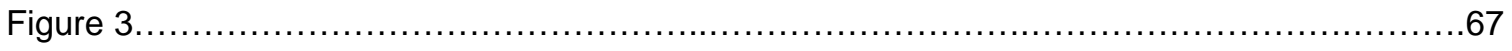

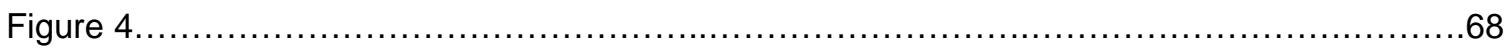

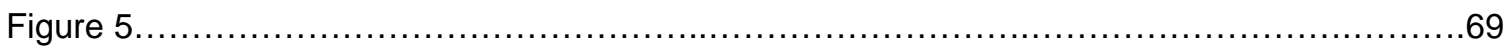


List of Tables

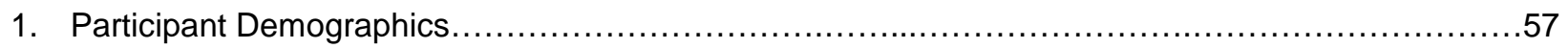

2. Mean and (Standard Deviation) Values for all Three Modes of Responding by Condition

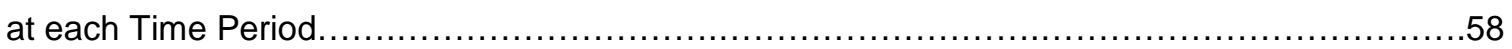

3. Descriptive Data for Aversiveness Ratings of High Fear, Low Fear, and Pain...........................59

4. Mean Scores and (Standard Deviations) for the Three Pre-Experiment Self-Report Meaures...........60

5. Correlations Among Dependent Variables and Self-Report Measures...............................61

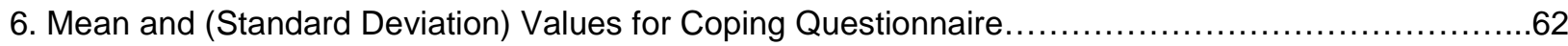

7. Correlations Among Dependent Variables and Coping Measure .....................................63 
List of Figures

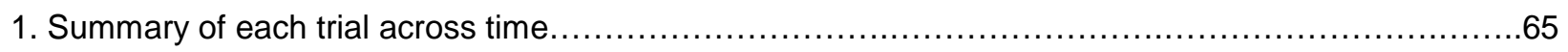

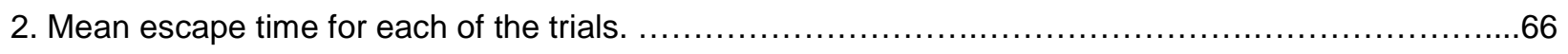

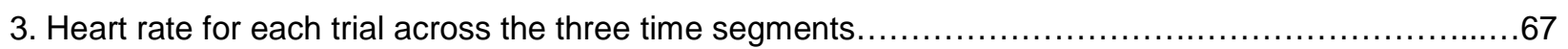

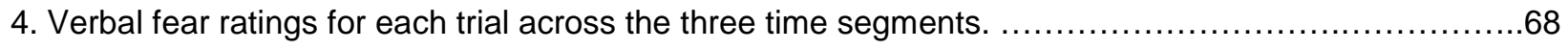

5. Verbal pain ratings for each trial across the three time segments. .................................69 
Order Effects 1

\section{Order Effects of Fear and Pain Induction}

Anxiety disorders are highly prevalent mental disorders within the general population according to the National Comorbidity Survey (Kessler et al., 1994). Further, the prevalence of anxiety disorders in medical settings is generally considered to be higher than the prevalence in the community (Roy-Byrne \& Katon, 2000). Given the pervasive, and often detrimental, effects that anxiety can have on an individual's level of functioning, a substantial amount of research has investigated the effects of anxiety on both frequency and severity of illness. Taken as a whole, the available literature indicates that individuals with anxiety disorders tend to have a higher incidence of unexplained physical symptoms, cardiac diseases, respiratory illnesses, gastrointestinal problems, and certain neurologic disturbances (see Roy-Byrne \& Katon for a review). Furthermore, anxious individuals have higher levels of disability (Marcus, Olfson, Pincus, Shear, \& Zarin, 1997) and higher levels of health care utilization (Katon et al., 1990; Simon, 1992). In sum, these studies indicate that anxiety and fear often complicate medical disorders and that those individuals diagnosed with both an anxiety disorder and a medical illness require more costly care compared to individuals who only have a medical illness.

In addition to medical disorders, a number of physical factors are influenced by anxiety. Pain perception and reporting appear to be significantly affected by the presence and severity of anxiety. A substantial amount of research has investigated the relation between anxiety and pain, and findings overwhelmingly have found a relation between these states (see Suinn, 2001 for a review). The degree and even direction of this relation, however, is still the subject of some debate. The general purpose of this experiment was twofold: (a) to further investigate the relation between fear and pain, and (b) to specifically investigate the differential effects that these two states may have on one another. To provide a theoretical and methodological framework, the first three sections of this paper will discuss concepts relevant to an analysis of the differential effects of fear and pain. The first section will discuss current conceptualizations of fear, anxiety, and pain. The second section will discuss conceptual and empirical studies directly addressing the relation between fear and pain. Specific attention will be paid to research that discusses fear's affect on pain, and pain's affect on fear. Finally, the third section briefly will discuss 
related and relevant constructs that can affect fear and pain. A summary incorporates these sections and provides an outline for the present experiment on the relation between fear and pain.

Current Conceptualizations of Fear, Anxiety, and Pain

Fear and Anxiety

The terms fear and anxiety often are used interchangeably in the literature; however, there are distinct differences between these emotional states. McNeil, Turk, and Ries (1994) defined fear and anxiety as states characterized by verbal reports of distress, physiological arousal, behavioral activation, and cognitive disruption. Anxiety, however, was defined as being associated with more cognitive symptoms and less physiological activation than fear. Barlow $(1988,1991)$ has defined anxiety as a negative mood state characterized by marked negative affect and somatic symptoms of tension in which a person anticipates and worries about future danger or problems that are perceived as uncontrollable. Taken together, these definitions view anxiety as more anticipatory in nature; an individual thinks about encountering the specific stimuli, and arousal (i.e., behavioral, cognitive, physiological) is the result. By contrast, McNeil et al. view fear as a more severe physiological reaction to the presence of the specific stimuli. In this case, the person actually encounters the feared stimulus, or the realistic threat of it, and significant physiological arousal is the result. The individual is likely to escape, or flee, from the situation. In the present paper, the label "fear" will be used to describe the state of physiological and emotional arousal associated with exposure to a potentially threatening situation or anticipation of such a situation, although it is recognized that the term "anxiety" may be more appropriate depending on individual participant's reaction to the experimental procedure.

\section{Pain}

Pain is a ubiquitous phenomenon that affects human beings across the lifespan. Despite this universality of the pain experience, pain as a concept is not fully defined or understood. Historical conceptualizations of pain, none of which are entirely accurate or complete, include emotional descriptions, sensory and physiological definitions, and classifications of behavioral responses to environmental stimuli (Tarnowski, Brown, Dingle, \& Dreelin, 1998). The complexity of the pain experience arises because of the: (a) complexity of the central nervous system (Weinstein, 1991), which transmits 
sensory pain signals, (b) intensity of the painful stimulus (Weinstein; Sorrell et al., 2001), (c) social and environmental variables (e.g., McGrath, 1994), (d) person's past experience and learning history (Staats, Hekmat, \& Staats, 1996), and (e) affective and cognitive variables (McGrath). Perhaps the most inclusive and complete definition of pain was forwarded by the International Association for the Study of Pain (IASP; 1994), which states that pain is, "an unpleasant sensory or emotional experience associated with actual or potential tissue damage, or described in terms of tissue damage (p. 211)." At its core, the IASP definition states that pain is an aversive experience, associated with real or anticipated tissue damage. Further, this definition recognizes pain as an experience unique to the individual, based on either physical insult to the body (e.g., tissue damage) or emotional variables (e.g., fear, depression) or both. Currently, the IASP definition of pain is perhaps the most used within the scientific and clinical communities, and, although it is somewhat vague, it accounts for many of the variables listed above which serve to complicate the assessment and treatment of pain problems.

Empirical Work Regarding the Relation Between Fear and Pain

The majority of available research is concerned with the effects of fear on pain. This will first be discussed, and then the limited amount of research investigating the effects of pain on fear will be outlined.

The relation between "negative" emotions (e.g., anger, depression, fear) in general and pain was first articulated in the Gate Control Theory of Pain (Melzack \& Wall, 1965), which defines pain primarily in terms of physiological activity. In 1982, Melzack and Wall hypothesized that central nervous system activity that results from negative emotions tends to intensify the physical experience of pain, thereby indicating that a positive relation existed between these states and pain. Although their specific hypothesis regarding the relation between physiological activity and pain level has not been entirely supported, a positive correlation between fear and pain does appear to exist. Specifically, this hypothesis has been empirically supported in various clinical populations, such as highly anxious dental (Vassend, 1993) and chronic pain patients (McCracken, Faber, \& Janeck, 1998). Rhudy and Meager (2000) found that experimentally induced anxiety was associated with decreased tolerance to painful stimulation. Furthermore, multiple treatment studies have indicated a positive relation between fear and pain level in 
patients undergoing invasive surgical interventions (e.g., Nelson, Zimmerman, Barnason, Nievenn, \& Schmaderer, 1998; Thomas, Heath, \& Rose, 1990). As additional evidence of the positive correlation between pain and fear, some investigators have reported that persistent pain appears to be prevalent in patients with panic disorder (Asmundson, Walker, Furer, \& Kjernsted, 2000; Schmidt \& Telch, 1997).

Unfortunately, the effect of fear on pain appears to be more complex than predicted by the Gate Control Theory. At least two studies have found that only certain types of fear lead to an increase in pain. Both Dougher, Goldstein, and Leight (1987) and Weisenberg, Aviram, Wolf, and Raphaeli (1984) found that individuals only reported increased pain when their fear or anxiety was somehow causally related to the painful stimulus. In other words, pain level only increased when fear or anxiety was a result of the painful stimulus or a result of anticipating the stimulus. Taken together, these two studies indicate that only pain-related fear that is somehow related to the painful stimulus, leads to an increase in reported pain levels. Further studies have indicated that fear which is not relevant to the specific source of the experienced pain actually reduces pain reports (Al Absi \& Rokke, 1991). In addition, it appears that the degree to which an individual attends to the fearful stimuli influences pain responding. A number of studies have indicated that attention to a painful stimulus was highly correlated with increased pain reports (Arntz, Dreessen, \& Merckelback, 1991; McCracken, 1997), regardless of fear level (Arntz \& De Jong, 1993). Eccleston and Crombez (1999) further argued that pain supersedes other demands for attention in organisms because they are evolutionarily disposed to respond to pain.

Although the above studies have largely investigated the effects of fear on pain, there has been some investigation into the effect of pain on fear. In 1980, Bolles and Faneslow proposed the perceptualdefensive-recuperative (PDR) model of fear and pain. This theoretical paradigm, based on animal models, argues that fear and pain are competing drive states, and that when an organism is injured, the "fear system" is activated, resulting in defensive and possibly escape behaviors, and that the pain system is inhibited. Only later, when the organism is safe, will pain predominate over fear, so as to facilitate recovery. Otherwise stated, this inhibition of pain remains until the threat is removed, then feelings of pain return, which motivates healing and recuperative behaviors on the part of the organism. Thus, fear and pain are two states that tend not to occur simultaneously. Other, more recent studies, have found that 
behavioral displays of pain, along with catastrophic cognitions and somatic sensations, predicted fear in a sample of patients with low back pain undergoing a physical examination (Hadjistavropoulos \& Lachapelle, 2000). These findings support previous research, which found that individuals with chronic pain generally experience significant levels of fear (see Asmundson, 1999, for a review). This research also supports a model of pain, fear, and anxiety that is extremely complex, in which these constructs affect each other in a multidirectional manner. In sum, the above studies underscore the importance of emotional variables, specifically anxiety and fear, in determining pain intensity. However, the field lacks a comprehensive model of exactly how these constructs interact with one another and how this interaction affects behavior. In addition, inconsistent findings exist in the literature regarding the relation between fear and pain and the majority of studies have been directed toward the evaluation of the effect of fear on pain.

\section{Constructs Related to Fear and Pain}

In addition to the variables that influence responding to painful and fearful stimuli, a number of other psychological constructs appear to be important in determining behavior resulting from feelings of pain or fear. Four pertinent variables and their relation to fear or pain are detailed below.

\section{Anxiety Sensitivity}

Anxiety sensitivity is defined as the extent to which one believes that feelings of anxiety or physiological arousal can have harmful consequences (Reiss, Peterson, Gursky, \& McNally, 1986). With regard to pain, anxiety sensitivity appears to influence pain responding, both behaviorally and cognitively. Specifically, high anxiety sensitivity is associated with elevated levels of pain-related distress, avoidance of potentially painful situations, and poorer treatment outcome in chronic pain patients (Asmundson, 1999). Further, Schmidt and Cook (1999) found that anxiety sensitivity level was significantly correlated with pain and anxiety severity ratings in individuals diagnosed with panic disorder undergoing a laboratory pain-induction procedure. Available research also suggests a positive correlation between reactivity to anxiety-inducing stimuli and anxiety sensitivity (Lejuez, O'Donnell, Wirth, Zvolensky, \& Eifert, 1998). In sum, available research suggests that anxiety sensitivity tends to have a significant affect on responding 
to any aversive stimulus (e.g., pain, fear) in which those individuals high in anxiety sensitivity tend to have more severe and negative reactions.

\section{Depression}

Associations between pain and depression have been found consistently in both acute and chronic pain populations. Fishbain, Cutler, Rosomoff, and Rosomoff (1997) reviewed 191 studies concerned with the relation between pain and depression and found the prevalence of depression is much more widespread in chronic pain patients than in controls. Further, a recent door-to-door survey in Europe indicated that almost one-third of individuals reporting some type of pain-related disability have significant depressive symptomology (Rethelyi, Berghammer, \& Kopp, 2001). Given the high comorbidity rate between chronic pain and depression, many investigators have focused their attention on the exact effect of depression on pain. The available literature suggests that depression is associated with significantly more frequent and severe pain reports, in both chronic pain (Krause, Wiener, \& Tait, 1994)

and acute pain (Bengtson, Herlitz, Karlsson, \& Hjalmarson, 1996). Further, feelings of depression appear to precipitate high levels of escape behavior and pain complaints in studies of experimentally induced emotion (e.g., Carter et al., in press; Zelman, Howland, Nichols, \& Cleeland, 1991).

\section{Fear of Pain}

Phobic levels of fear regarding painful situations, generally referred to as pain-related anxiety or fear of pain, can have a profound affect on pain responding. Lethem, Slade, Troup, and Bentley (1983) proposed a model in which an individual who is highly fearful of painful experiences tends to avoid any situations where pain is likely to occur. This avoidance strategy is hypothesized to have a number of negative physical and psychological consequences (e.g., loss of physical mobility, increased feelings of inadequacy) and increases the likelihood of impaired physical functioning and exaggerated pain perception. Evidence for Lethem et al.'s model appears both in applied (e.g., McCracken \& Gross, 1993; Sperry-Clark, McNeil, \& Ciano-Federoff, 1999; Zvolensky, Goodie, McNeil, Sperry, \& Sorrell, 2001) and experimental (e.g., Crombez, Vlaeyen, Heuts, \& Lysens, 1999) settings. As Vlayen and Linton (2000) note, the current state of the pain fear-avoidance literature contains evidence which strongly links excessive levels of fear of pain to exaggerated pain responding, and can often substantially interfere with 
functioning. In contrast, low levels of fear of pain often are associated with a more "confrontive" approach towards painful experiences. This approach to coping with painful experiences leads to more adaptive responses and actually appears to decrease the perception of pain severity. As a construct, fear of pain appears similar to specific phobias, where an individual will irrationally avoid all stimuli associated with the feared object. Over time, more and more situations or stimuli are avoided and the end result is a loss of functioning. The facet which differentiates and makes fear of pain more distressing than other phobias is that it is not only associated with a decrease in functioning, but also an increase in pain perception.

\section{Coping}

The type of strategy used to cope with pain has been associated with psychological adjustment and treatment outcome in individuals with chronic pain (e.g., Spinhoven \& Lissen, 1991). In general, coping strategies have been conceptualized in terms of active and passive, with active coping being the more effective and adaptive. Active coping was defined by Brown and Nicassio (1987) as including strategies used to control or maintain adequate levels of functioning in spite of pain; in contrast, passive coping strategies give up control or allow pain to negatively impact functioning. Active coping strategies include distracting oneself, ignoring the pain, and doing an alternate activity. Examples of passive coping strategies are thinking catastrophic thoughts, relying on health care providers to fix the problem, and relying on divine intervention. An alternative conceptualization differentiates these strategies based on whether the individual relies upon internal (active) or external (passive) resources to control pain (SnowTurek, Norris, \& Tan, 1996). Active strategies may be more effective because they allow behavior that affects a person's perception of the pain, which may in turn increase their perceived control over it or may decrease it's impact on functioning.

\section{Summary and Statement of the Problem}

The current state of the literature illustrates the complexity of pain responding. Contrary to historical conceptualizations of pain, which viewed pain perception as being determined only by physical stimuli (e.g., tissue damage), contemporary research has revealed a number of emotional states which, along with other psychosocial factors, influence pain perception. Emotional states such as depression and anxiety sensitivity appear to increase pain responding. Similarly, states such as anxiety and fear 
appear to generally make pain worse. The finding regarding fear and anxiety, however, is not universal across all studies; some investigators have found evidence of such an effect, while others have not. This complexity in the interaction between fear and pain has fueled a great deal of research and a number of questions remain unanswered.

The field still lacks a comprehensive model of exactly how fear and pain interact with each other. The majority of the literature focuses on the effect of fear on pain; however, pain likely also has a substantial effect on fear. For example, some preliminary work in our laboratory (Sorrell et al., 2001) confirms that simply increasing the intensity of the pain that one experiences can determine individual responses to both painful and fearful stimuli. These findings, coupled with the fact that effects of pain on fear have not been the subject of much empirical study, indicate that it may be useful to investigate the differential effects that these states have on one another.

Furthermore, current pain and fear models do not explain how the relation between these variables originates. A number of studies have indicated significant correlations between pain and fear; however, a causal model has yet to be developed. The implications of one's learning history and previous experience with pain or fear have yet to be investigated as variables that may influence behavior. An experimental manipulation of stimulus presentation order may be helpful in the construction of a causal model of pain and fear. Additionally, the literature still has not clearly defined the role of pre-existing pain on fear or pre-existing fear on pain. The clinical implications of such findings include issues of accurate treatment targeting and differential diagnoses.

Finally, current models do not fully define the role of preexisting individual differences on individual responding. A number of constructs (e.g., anxiety sensitivity, depression, fear of pain) have established relations with fear or pain when stimuli are presented individually; however, the effects of these constructs on a more complicated model, one with multiple stimuli, have not been investigated. Furthermore, how these variables predict or change the relation between fear and pain is not currently known. Therefore, a more thorough investigation of the influences of these constructs is needed. 
Hypotheses

Given the sometimes contrary and complicated conclusions that have been drawn from previous research, the present study sought to improve current models of fear and pain by investigating the differential effects that these states may have on one another. Because much of the previous research regarding the relation between fear and pain has used correlational designs, a factorial design was used because it allowed for a more thorough investigation of how these two states are effecting one another. Further, this design allowed us to experimentally manipulate the order in which participants experienced painful and fearful stimuli (i.e., stimulus presentation order). Two levels of fear were used and allowed an examination of the effects that different fear intensities can have on participant responding. Additionally, a number of questionnaires, tapping constructs relevant to fear and pain, were completed by participants before the experimental procedure in order to investigate how pre-existing differences may influence participant responding. The following hypotheses were tested:

(1) It is predicted that participants who experience high fear will show greater distress (i.e., behavioral, physiological, and verbal) to fearful and painful stimuli compared to participants who experience low fear, regardless of the order in which the stimuli are encountered.

(2) Based on current research, it is hypothesized that there will be a significant effect of stimulus presentation order on participants' responding. The literature provides some evidence that pain is a noxious stimulus that tends to capture the attention of the individual (Eccleston, 1995; Eccleston \& Crombez, 1999). It is therefore hypothesized that those individuals who experience pain first will exhibit greater distress compared to those who experience fear first. In sum, it is hypothesized that pain will exacerbate the effects of the fearful stimulus.

(3) Based on the main effects predicted above, participants will exhibit the greatest distress when they experience pain first and then high fear, compared to the other three conditions. 
In addition to the above hypotheses, the questionnaires included in the present study allow a number of additional hypotheses to be tested.

(4) Those individuals who report higher basal levels of fear of pain, anxiety sensitivity, and depression will exhibit greater arousal and distress during the experimental procedure compared to participants reporting lesser severity.

(5) Active coping methods will be associated with less distressed behaviors, and passive coping with more distressed behaviors.

\section{Method}

\section{Participants}

Forty-eight undergraduate students (24 males and 24 females) were included in the present study and received either $\$ 10$ or class extra credit for their participation. Table 1 lists the demographic characteristics of the sample. Eligibility for the study also was evaluated using criteria previously utilized in our laboratory (Sorrell et al., 2001) and a medical screening questionnaire and semi-structured individual interview adapted from other similar research (e.g., Forsyth, Eifert, \& Thompson, 1996). Participants were excluded from the study if they had a positive history of panic attacks, asthma or other respiratory problems, heart trouble, serious psychopathology, were presently pregnant, or had previously participated in a study utilizing $\mathrm{CO}_{2}$-enriched air. As a group, participants were healthy and, consistent with their ages, had experienced low to moderate amounts of pain in their lifetimes. Only 5 (10\%) reported any experience with chronic pain. Slightly more than half $(\underline{n}=27,56 \%)$ had never had a surgery and $42(87.5 \%)$ reported never having been hospitalized. Only one female had ever given birth. Eligible individuals were randomly assigned to a pre-determined trial sequence, randomized using a Latin Square procedure. This procedure allows a deliberate randomization of experimental trails and is used to control any sequencing effects. There were 24 possible arrangements of the four trials, each was experienced by one male and one female. Participants were randomly assigned to a particular trial arrangement. All participants completed a written consent prior to the study and were debriefed at its conclusion. 


\section{$\underline{\text { Apparatus }}$}

\section{Pain Induction}

A number of devices exist to induce pain experimentally, however, their reliability to consistently produce pain varies. One device that provides reliable laboratory-induced pain and allows pain intensity to be quantified over time is the algometer pressure pain stimulator (Rainwater \& McNeil, 1991). In the present experiment, pain was induced using an algometer pressure pain stimulator originally developed by Forgione and Barber (1971). The algometer design used was based on experimentation by Dougher et al. (1987), and was diagrammed by Rainwater and McNeil. Pain is produced by placing weights of differing mass on top of a platform attached to a dull Lucite blade positioned on the second phalanx of a single finger. The algometer produces a building, aching pain. Pain onset and severity can be varied based on the weight that is utilized. For the present study, a weight of $750 \mathrm{~g}$ was utilized. Participants were exposed to the pain stimulus for no longer than $300 \mathrm{~s}$ per experimental condition.

\section{Fear Induction}

Reliable fear induction also has proven difficult to accomplish in the laboratory (e.g., Sorrell et al., 2001; Carter et al., in press). New technologies are available which have been shown to reliably induce fear-like states. For example, carbon dioxide $\left(\mathrm{CO}_{2}\right)$ enriched air is one experimental methodology that can be used to evoke fear-like responses in highly controlled settings (Lejuez, Forsyth, \& Eifert, 1998; Sanderson \& Wetzler, 1990; Zvolensky \& Eifert, 2001). Carbon dioxide has been shown to produce fearlike visceral responses analogous to the key characteristics of panic attacks (for a review, see Zvolensky \& Eifert). These sensations of fear appear to be a direct effect of the physiological arousal produced by the $\mathrm{CO}_{2}$. Finally, $\mathrm{CO}_{2}$ induction represents a safe and valid method to provoke fear responses (Harrington, Schmidt, \& Telch, 1996).

One of two levels of $\mathrm{CO}_{2}$ enriched air was used to induce different levels of fear. An automated apparatus, described by Lejuez, Forsyth et al. (1998), was utilized for $\mathrm{CO}_{2}$ delivery. $\mathrm{A} \mathrm{CO}_{2}$ concentration of either $5 \%$ (i.e., "low fear") or 15\% (i.e., "high fear") was administered, depending on the experimental condition. Both levels have been used in the past to gradually produce a sustained level of arousal (Zvolensky \& Eifert, 2001). Participants breathed $\mathrm{CO}_{2}$-enriched air for no longer than $300 \mathrm{~s}$ per 
experimental condition.

\section{Laboratory Environment}

The experiment was conducted in a laboratory suite in which two adjacent rooms were connected via intercom. A computer, physiological data acquisition equipment, and the $\mathrm{CO}_{2}$ apparatus all were in a control room. There was a separate $9 \mathrm{ft} \times 12.5 \mathrm{ft}$ room for the participant and the algometer device. Necessary cables ran from the control room to the participant room, and vice versa.

There were four trained experimenters, two male and two female. For collection of data from an individual participant, there was one experimenter in the control room who did not directly interact with the participant. There was a second experimenter who interacted with the participant to get informed consent, administer instructions and questionnaires, and to operate the algometer. Participants were seated upright in an overstuffed chair across a table from an experimenter, who also was seated.

\section{Experimental Design}

In order to further investigate the effects of fear and pain on one another, the present study manipulated stimulus presentation order of fear and pain-provoking stimuli to 48 individuals. Participants received a single stimulus (i.e., either fear or pain) for $30 \mathrm{~s}$, and then received both stimuli (i.e., fear and pain) for no more than 270 additional seconds. A $2 \times 2$ within subjects design was employed. Factors were as follows: (a) $\mathrm{CO}_{2}$ gas level (5\% vs. $15 \%$ ), and (b) order of first stimulus presentation (i.e., pain vs. fear). This design yielded four different trials; each participant experienced all four trials. The four trials are as follows: (a) $15 \% \mathrm{CO}_{2}$ (i.e., "high fear") followed by $15 \% \mathrm{CO}_{2}$ and pain $(\mathrm{HF}=>\mathrm{HF}+\mathrm{P})$, (b) pain followed by $15 \% \mathrm{CO}_{2}$ and pain $(\mathrm{P}=>\mathrm{HF}+\mathrm{P})$, (c) $5 \% \mathrm{CO}_{2}$ (i.e., "low fear") followed by $5 \% \mathrm{CO}_{2}$ and pain $(L F=>L F+P)$, and $(d)$ pain followed by $5 \% \mathrm{CO}_{2}$ and pain $(P=>L F+P)$. Stratified random allocation was used to assign participants equally across gender, experimenter gender, and trial sequence.

\section{Dependent Measures}

\section{$\underline{\text { Overt behavior }}$}

Individuals were allowed to discontinue any of the trials at any time (i.e., escape), even before it had begun (i.e., avoidance). An overt measure of escape was calculated by subtracting the time that the participant spent in the condition from total condition time (300 s). 


\section{Physiological}

An IBM compatible microcomputer, fitted with a Scientific Solutions Labmaster interface board and specialized software (Cook, Atkinson, \& Lang, 1987), controlled a Coulbourn Instruments no. S75-01 High Gain Bioamplifier/Couller that filtered and amplified electrocardiogram (ECG) data to obtain heart rate. The ECG data was input to a Schmitt trigger apparatus (including a CI no. S21-06 Bipolar Comparator and no. S51-12 Dual Retriggerable One-Shot) that output a pulse after detecting an R wave. Three $\mathrm{Ag} / \mathrm{AgCl}$ electrodes equipped with adhesive collars and filled with a .05 molar solution of $\mathrm{NaCl}$, were attached to participants. One electrode was placed just below the right clavicle, one below the left clavicle, and the ground electrode was placed on the left side of the torso, just below the rib cage. Interbeat intervals were recorded and later transformed into beats per minute (bpm).

\section{$\underline{\text { Self Report of Emotional and Pain States }}$}

Subjective Units of Distress Scale. Subjective Units of Distress scales (SUDs; Wolpe, 1958) were utilized to obtain a separate index of fear, pain, and aversiveness levels. Each measure was presented as a visual analogue scale (VAS), and ranged from zero (no fear, pain, or aversiveness) to nine (maximum fear, pain, or aversiveness imaginable in the given situation). Participants made ratings of fear, pain, and aversiveness three times during each trial: before the trial began, just before the second stimulus was introduced, and after the trial was discontinued. Because participants wore a mask, they were asked to circle SUDs ratings on a sheet of paper when prompted to do so. The aversiveness ratings were included only to compare the three different stimuli (i.e., high fear, low fear, and pain) in regard to the overall discomfort and distress that they induced in participants.

Aversiveness ratings. At the end of the experimental procedure, all participants rank ordered the three stimuli (i.e., low fear, high fear, pain), in relation to one another, from most aversive to least aversive.

\section{Descriptive Questionnaires}

Anxiety Sensitivity Index. The ASI (Reiss et al., 1986) is a 16-item instrument designed to measure fear of anxiety-related sensations. Individuals rate the degree to which they are concerned about possible aversive consequences of anxiety symptoms on a 5 -point Likert scale $(0=$ very little to $4=$ 
very much). Because of the presence of individual differences in responding to potentially anxietyprovoking situations, a measure able to tap into and quantify these differences was included in the present study. The ASI has excellent internal consistency and test-retest reliability (McNally, 1996). Research indicates that the factor structure of the ASI is comprised of a single, higher order factor (Global Anxiety Sensitivity) and three lower-order factors (i.e., Physical, Psychological, and Social Concerns; Stein, Jang, \& Livesley, 1999). Because of ethical considerations, individuals who had elevated scores on ASI (e.g., scores > 30) were excluded from participation.

Beck Depression Inventory-II. The Beck Depression Inventory-II (BDI-II; Beck, Rush, Shaw, \& Emery, 1979) is a 21 -item assessment with a 4-point Likert-type rating for each question ranging from no endorsement of depressive symptoms to a strong endorsement. It is designed to assess for common cognitive, affective, and vegetative clinically relevant symptoms of depression. Research evaluating the reliability and validity of the BDI-II has indicated that it is an useful index of depression (Beck, Steer, \& Garbin, 1988). Individuals with elevated BDI-Il scores (i.e., scores > 18) were excluded from participation.

Fear of Pain Questionnaire-III. Because of fear of pain's effect on pain responding, the Fear of Pain Questionnaire-III (FPQ-III; McNeil \& Rainwater, 1998), a 30-item, empirically derived instrument designed to assess for specific fear or anxiety related to pain, was administered. Individuals rate their fear of experiencing the pain associated with pain-related events on five-point, Likert-type scales. The FPQ-III measures fear along three dimensions: severe pain, minor pain, and medical pain. A total score is available, as well as scores for each subscale. The FPQ-III has demonstrated good reliability and construct validity (e.g., Hursey \& Jacks, 1992; McNeil \& Rainwater).

Coping Questionnaire. Because coping style appears to be related to pain perception (Cioffi \& Holloway, 1993; Snow-Turek et al., 1996), a measure of coping style was developed. This measure was based on the 50-item Coping Strategies Questionnaire (CSQ) developed by Rosenstiel and Keefe (1983). It was necessary to develop a measure that inquired about coping methods for both pain and fear and that asked participants specifically about their method of coping with any discomfort associated with the experimental procedure, rather than about typical coping methods. The coping questionnaire developed for the present study was composed of seven questions, one for each of the seven types of coping 
identified by the CSQ. These scales were diverting attention, reinterpreting pain sensations, use of coping self-statements, ignoring pain sensations, praying and hoping, catastrophizing, and increasing activity level. Using the same 0-6 Likert-type scale as the CSQ, participants rated how frequently they utilized specific coping strategies. Anchor points were at 0 (i.e., "Not at all) and at 6 (i.e., "All the time"). Appendix A displays the questionnaire.

\section{Procedure}

Undergraduate students were asked to participate in the present study. Participants were recruited using class announcements and posted advertisements in the Department of Psychology. They were informed that the study consisted of monitoring individual responses to fear and pain in the laboratory. Students willing to participate were then scheduled for participation in the study. Upon arriving at the laboratory, a semi-structured interview was conducted to ensure eligibility status.

Eligible participants were given a consent form (Appendix B), which was reviewed with them. They further were informed that they could discontinue participation in any of the trials at any time, which allowed a measure of tolerance to be calculated. Following the completion of the consent form, participants completed descriptive measures (i.e., FPQ-III, ASI, BDI-II), which took approximately one half hour. Once completed, electrodes for the physiological recording instruments were attached and participants were asked to close their eyes and relax for $300 \mathrm{~s}$ while pre-trial physiological measures were obtained.

Following pre-trial measurement, one of the participant's fingers (i.e., right/left index, right/left middle) was inserted into the algometer and the mask used for the administration of $\mathrm{CO}_{2}$-enriched air was placed over their mouth and nose. A different finger was used for each trial; order of finger use was randomized. Next, standardized instructions (see Appendix C) were given and participants were specifically informed that they were free to discontinue any of the trials at any time by touching a small "Stop" sign, which was approximately five inches in diameter and located in front of them throughout the experiment. Further, participants were informed which level of fear and which stimulus presentation order they would experience in the coming trial and were then asked to give pre-trial ratings of current levels of fear, pain, and aversiveness on the VAS. At this point, the trial began and one stimulus was presented 
(i.e., $5 \% \mathrm{CO}_{2}, 15 \% \mathrm{CO}_{2}$, or $750 \mathrm{~g}$ weight). Participants were asked to rate their fear, pain, and aversiveness levels at the $20 \mathrm{~s}$ mark of the trial. This rating was given at $20 \mathrm{~s}$ to allow participants enough time to complete ratings before the second stimulus was introduced. Further, it also served as a manipulation check to ascertain the effects of the first stimulus. The first stimulus initially was presented for 30 seconds. At the conclusion of this period, the second stimulus was added. In order to provide adequate amounts of data for the present study, participants were asked to stay in each trial at least $60 \mathrm{~s}$ (i.e., $30 \mathrm{~s}$ with the first stimulus plus $30 \mathrm{~s}$ with both stimuli). Data from those individuals who failed to stay in each trial at least $60 \mathrm{~s}$ were replaced $(\underline{n}=4)$, as it did not allow an evaluation of the proposed hypotheses. Following the second phase of the condition (maximum time $=270 \mathrm{~s}$ ), both stimuli were discontinued and participants gave a third and final rating of their level of fear, pain, and aversiveness. See Figure 1 for a summary of each trial across time. After this final rating, a final $300 \mathrm{~s}$ measurement of heart rate occurred. Participants then repeated this sequence for the next three trials and heart rate measurements. After the final post-experiment heart rate measurement, participants completed the coping questionnaire and rank ordered the three stimuli in terms of aversiveness. Finally, they were debriefed and any questions were answered. A number of tones sounded throughout the procedure in order to inform participants of their position in each of the trials. See Appendix D for a procedural flow chart.

Results

\section{Statistical Approach and Data Reduction}

Data were collected for 48 participants on overt behavioral, physiological, and self-report measures. Data from a total of eleven individuals needed to be replaced. As previously noted, four of these individuals' data were replaced because they failed to remain in each trial for the required minimum of $60 \mathrm{~s}$. Further, four individuals were excluded from participation in the experiment because of elevated scores on the BDI-II (e.g., score > 18); one of these individuals also had a score of greater than 30 on the ASI. Two participants' data needed to be replaced because of equipment malfunction. Finally, one participant discontinued the experiment in its entirety at the conclusion of the first trial as he found it to be too uncomfortable. 
Because repeated measures research designs often violate the assumption of sphericity (Tabachnick \& Fidell, 2001; Weinfurt, 1995), which results in inflated type I error rates, multivariate analyses of variance (MANOVAs) were performed in the present experiment. The multivariate approach to repeated measures designs does not assume sphericity in the data and is an appropriate method of analyzing within-subjects research designs (see Tabachnick \& Fidell). In the present experiment, MANOVAs were used to investigate the effects of $\mathrm{CO}_{2}$ level and stimulus presentation order across all three modes of responding. The multivariate statistic used to test significance was Wilks $\lambda$. This statistic was selected because of its power to detect group separation and also because it gives an indication of the unexplained variance in dependent measures (Weinfurt, 1995). For escape time, a 2 (stimulus presentation order: fear followed by pain vs. pain followed by fear) X 2 (fear level: high vs. low) MANOVA was performed. For all other dependent measures (i.e., heart rate, verbal report of fear, verbal report of pain), 2 (stimulus presentation order: fear followed by pain vs. pain followed by fear) $X 2$ (fear level: high vs. low) X 3 (time segment: pre-trial rating/measurement, $30 \mathrm{~s}$ rating/measurement, and post-trial rating/measurement) MANOVAs were performed. For the time segment variable, measurements at the first time segment were the pre-trial rating. Furthermore, measurements at the second time segment provided manipulation checks regarding the effects of the single stimulus (i.e., fear or pain) experienced during the first $30 \mathrm{~s}$. The third segment provided comparisons regarding the effects of both stimuli (i.e., fear and pain). For the third segment, median heart rate values from the second $30 \mathrm{~s}$ (i.e., 31-60 s) of each trial was used, as this time period allowed the most parsimonious comparisons across participants who had differing tolerance times. In addition, for verbal reports of fear and pain, the final rating made by participants after escape had occurred or the trial had ended were used. Table 2 summarizes data obtained from the three response modalities by condition at each of the time segments.

When necessary, simple effects tests were used to follow-up any indicated interactions. Because of the large number of possible follow-up tests, Bonferroni corrections were used to control for inflated type I error rates in these anlyses. Post hoc analyses were performed at each of the three time segments, in which four comparisons between the different trials were possible, therefore the Bonferroni-corrected $\alpha$ 
$=.05 / 4=.0125$. Furthermore, when ratings for the individual trials were analyzed over the three time segments, three comparisons were possible, and the Bonferroni-corrected $\alpha$ was set at $.05 / 3=.0167$. In order to investigate any effects of gender on participant responding, participant gender and experimenter gender were included as between-subjects variables in supplemental analyses. Specifically, five-way MANOVAs [i.e., 2 (stimulus presentation order: fear followed by pain vs. pain followed by fear) $X$ 2 (fear level: high vs. low) $\times 3$ (time segment: pre-trial rating rating/measurement, $30 \mathrm{~s}$ rating/measurement, and post-trial rating/measurement) $X 2$ (participant gender: female vs. male) $X 2$ (experimenter gender: female vs. male] were performed. Because of the exploratory nature of these supplemental analyses, no corrections for type I error were used.

\section{Escape Time}

Escape was defined as a participant stopping any of the trials after it started but before the end of the $300 \mathrm{~s}$ condition. Escape times were calculated by subtracting the time participants spent in each trail from the total possible trial time; therefore, higher escape times were associated with more distressed behavior. With regard to the number of participants who escaped from each of the trials, 22 males (91.7\%) and 22 females (91.7\%) escaped the HF => P+HF trial, 21 males (87.5\%) and 21 females $(87.5 \%)$ escaped the $\mathrm{P}=>\mathrm{P}+\mathrm{HF}$ trial, 5 males $(20.8 \%)$ and 7 females $(29.2 \%)$ escaped the $\mathrm{LF}=>\mathrm{P}+\mathrm{LF}$ trial, and 4 males (16.7\%) and 7 females (29.2\%) escaped the $P=>P+L F$ trial. Regardless of stimulus presentation order, the majority of participants escaped from the high fear conditions and did not escape from the low fear conditions.

Principal Analyses

A significant main effect of $\mathrm{CO}_{2}$ level on escape time was indicated, $\underline{F}(1,47)=144.86, \underline{p}<.001$; faster escape times were associated with high fear $(\underline{M}=183.81 \mathrm{~s}, \underline{\mathrm{S}} . \mathrm{D} .=75.88 \mathrm{~s})$ relative to low fear $(\underline{\mathrm{M}}=$ $39.04 \mathrm{~s}, \underline{\text { S.D. }}=76.92 \mathrm{~s}$ ). No other main effects or interactions were significant. Figure 2 displays average escape time for participants across each of the four trials. See Appendix E for corresponding MANOVA table. 
Supplemental Analyses

When participant gender and experimenter gender were included in the factorial analysis for escape time, the results of the principal analyses were replicated with regard to the main effect of $\mathrm{CO}_{2}$ level. In addition, a main effect of gender was found, $\underline{F}(1,47)=4.30, \underline{p}<.05$; females $(\underline{M}=127.56 \mathrm{~s}$, $\underline{\text { S.D. }}=82.16 \mathrm{~s})$ escaped from each of the trials more quickly than males $(\underline{M}=95.29 \mathrm{~s}, \underline{\text { S.D. }}=66.01 \mathrm{~s})$. No other gender-related effects were significant. See Appendix F for the corresponding MANOVA table.

\section{Cardiac Response}

\section{Principal Analyses}

As noted previously, a $2 \times 2 \times 3$ MANOVA was performed to investigate differences in median heart rate responding. For heart rate, main effects were shown for fear level, $\underline{E}(1,47)=25.09$, $\underline{p}<.001$, stimulus presentation order, $\underline{\mathrm{F}}(1,47)=6.55, \underline{\mathrm{p}}<.05$, and trial segment, $\underline{\mathrm{F}}(2,46)=57.31, \underline{\mathrm{p}}<.001$. Further, two-way interactions were indicated between fear level and stimulus presentation order, $\underline{F}(1,47)$ $=6.49, \underline{p}<.05$, fear level and trial segment, $\underline{\mathrm{F}}(2,46)=22.44, \underline{\mathrm{p}}<.001$, and stimulus presentation order and trial segment, $\underline{F}(2,46)=14.99, \underline{p}<.001$. Finally, a significant three-way interaction (see figure 3 ) was observed among the variables, $\underline{F}(2,46)=8.79, \underline{p}<.001$. See Appendix $G$ for corresponding MANOVA table. Follow-up analyses are detailed below

Pre-trial comparisons. No significant differences in pre-trial rating heart rate among the four trials were revealed.

$30 \mathrm{~s}$ comparisons. At the end of $30 \mathrm{~s}$, no differences between the two stimulus presentation orders were indicated for low fear, regardless of stimulus presentation order. Conversely, a significant difference in heart rate was observed for stimulus presentation order at high fear for the second time segment, with higher heart rates in the $H F=>P+H F$ trial compared to the $P=>P+H F$ trial. With regard to differences between the two levels of fear, no differences were indicated when pain was experienced first. In those trials where fear was experienced first, however, greater heart rates were observed at the high level of fear compared to the low level.

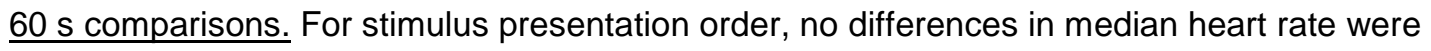
observed for the low level of fear. At the high level of fear, participants exhibited higher heart rates in the 
$\mathrm{HF}=>\mathrm{P}+\mathrm{HF}$ trial compared to the $\mathrm{P}=>\mathrm{P}+\mathrm{HF}$ trial. Finally, individuals who experienced high fear exhibited higher median heart rates than individuals who experienced low fear, regardless of stimulus presentation order.

Time segment comparisons. As a final post-hoc analysis, differences within each trial at each time period were analyzed. Heart rate significantly increased across all three of the time periods for all four trials with the exception of those trials in which pain was experienced first. Specifically, no increases in heart rate were observed at the second time segment (i.e., $30 \mathrm{~s}$ ) relative to the first (i.e., pre-trial rating) when pain was the first stimulus experienced.

\section{Supplemental Analyses}

When participant and experimenter gender were included in supplemental analyses, all main effects and interactions findings of the principal analyses were replicated. No effects of gender were indicated. See Appendix $\mathrm{H}$ for the corresponding MANOVA table.

\section{Verbal Reports of Fear}

\section{Principal Analyses}

Similar to the findings for heart rate, analyses based on participant's verbal ratings of fear indicated main effects for fear level, $\underline{F}(1,47)=47.72, \underline{p}<.001$, stimulus presentation order, $\underline{F}(1,47)=$ $6.95, \underline{p}<.05$, and trial segment, $\underline{\mathrm{E}}(2,46)=34.89, \underline{\mathrm{p}}<.001$. In addition, two-way interactions were indicated between fear level and stimulus presentation order, $\underline{F}(1,47)=9.44, \underline{p}<.005$, fear level and trial segment, $\underline{F}(2,46)=32.85, \underline{p}<.001$, and stimulus presentation order and trial segment, $\underline{F}(2,46)=3.43$, $\underline{\mathrm{p}}<.05$. Finally, a significant three-way interaction was observed among the three variables, $\underline{\mathrm{F}}(2,46)=$ $6.55, \underline{p}<.005$. Appendix I displays the corresponding MANOVA table. Follow-up comparisons are detailed below (see Figure 4).

Pre-trial comparisons. No differences in pre-trial fear ratings were indicated among the four trials.

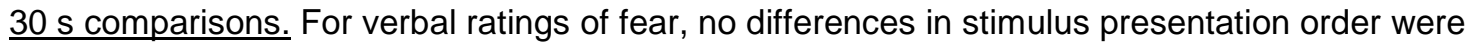
indicated at the low levels of fear, nor were there any differences when pain was experienced first. When the high level of fear was experienced first, however, participants reported higher levels of fear than when 
high fear was experienced second. Finally, when high fear was experienced first, fear ratings were higher than when low fear was experienced first.

Post-trial comparisons. For verbal ratings of fear, no differences were apparent between the two stimulus presentation orders for the low level of fear, although individuals who experienced high fear first had higher fear ratings than those who experienced high fear second. Finally, the high level of fear was associated with higher verbal ratings of fear relative to the low level of fear and regardless of presentation order.

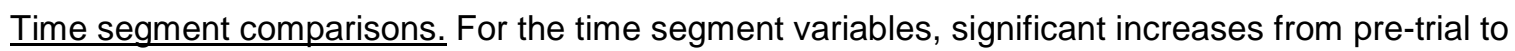
the $30 \mathrm{~s}$ measurement only occurred for the $\mathrm{HF}=>\mathrm{P}+\mathrm{HF}$ trial. From the $30 \mathrm{~s}$ rating to the post-trial rating, fear ratings increased significantly across all trials. See Figure 5.

\section{Supplemental Analyses}

All main effects and interaction findings for the principal analyses were replicated when the two gender variables were included in the analyses. Further, a significant interaction between participant gender and experimenter gender was indicated, $\underline{F}(1,44)=4.45, \underline{p}<.05$ and significant four-way interactions were revealed for stimulus presentation order, time segment, participant gender, and experimenter gender, $\underline{\mathrm{F}}(2,43)=5.22, \underline{\mathrm{p}}<.01$, and for fear level, stimulus presentation order, time segment, and experimenter gender, $\underline{\mathrm{F}}(2,43), \underline{\mathrm{p}}<.05$. Finally, a significant five-way interaction was indicated between all variables, $\underline{\mathrm{F}}(2,43)=4.81, \underline{\mathrm{p}}<.05$. For the significant post-hoc analyses, all mean differences were in the same direction. In general, females were more likely to rate their fear higher when in the company of a female experimenter than when they were with a male experimenter. Higher fear ratings in the presence of female experimenters were specifically observed at the pre-trial and $30 \mathrm{~s}$ ratings when fear was experienced first, at the pre-trial rating when high fear was experienced first, and at the final (post-trial) rating for the $P=>P+L F$ trial. No other significant differences were indicated. See Appendix $\mathrm{J}$ for the corresponding MANOVA table. 
Verbal Reports of Pain

\section{Principal Analyses}

As was the case with heart rate and fear ratings, for verbal report of pain, main effects were indicated for fear level, $\underline{F}(1,47)=13.07, \underline{p}<.001$, stimulus presentation order, $\underline{F}(1,47)=45.31, \underline{p}<$ .001 , and trial segment, $\underline{F}(2,46)=113.37, \underline{p}<.001$. Two-way interactions were indicated between fear level and trial segment, $\underline{\mathrm{F}}(2,46)=15.86, \underline{\mathrm{p}}<.001$, and stimulus presentation order and trial segment, $\underline{\mathrm{F}}$ $(2,46)=32.70, \underline{p}<.001$, but not for fear level and stimulus presentation order, $\underline{F}(1,47)=0.45, \underline{p}>.50$. Finally, a significant three-way interaction was observed, $\underline{F}(2,46)=7.61, \underline{p}<.001$. See Appendix $K$ for corresponding MANOVA table. Follow-up comparisons are detailed below and are displayed in Figure 5.

Pre-trial comparisons. As was the case with heart rate and verbal reports of fear, no differences were indicated for pre-trial ratings of pain among the four trials.

30 s comparisons. Trials in which participants experienced pain first were associated with greater pain ratings for both fear levels. No differences in pain ratings were observed between the high and low levels of fear at either of the stimulus presentation orders.

Post-trial comparisons. Higher pain ratings were associated with the $\mathrm{P}=>\mathrm{P}+\mathrm{HF}$ trials relative to the $H F=>P+H F$ trials. No such differences in pain ratings were observed at the low level of fear. In addition, differences between the two levels of fear were observed with lower pain ratings associated with the high level of fear for both stimulus presentation orders.

Time segment comparisons. When analyzed over time, pain ratings significantly increased across all time intervals and for all four trials with the exception of the pre-trial to $30 \mathrm{~s}$ rating for the $L F=>P+L F$ trial.

\section{Supplemental Analyses}

All findings for the principal analyses were again replicated when the gender variables were included. No gender effects were indicated. See Appendix L for the corresponding MANOVA table.

\section{Comparison of Stimuli Aversiveness}

At the conclusion of the experiment, participants were asked to rank order the three stimuli with regard to aversiveness. The majority of participants ranked the high fear as the most aversive, the painful 
stimulus as second most aversive, and the low fear as least aversive. Table 3 displays how each stimulus was rated across all participants and the mean ranking for each of the stimuli. A Kendall's Coefficient of Concordance was calculated to test whether participants were consistent in their rankings of the aversiveness of the three stimuli. This test allows a coefficient to be calculated which indicates the degree of agreement between raters and ranges from 0 (no agreement) to 1 (complete agreement). For the present analysis, the Kendall coefficient of concordance was .80 , indicating a large amount of consistency in rankings across participants. In order to investigate specific differences between the three ratings, follow-up comparisons were conducted using a Wilcoxin test, as recommended by Green, Salkind, and Akey (2000). These analyses indicated that high fear was ranked as more aversive than low fear, $\underline{z}=-$ $6.43 ; \underline{p}<.001$, and pain, $\underline{z}=-5.15 ; \underline{p}<.001$. Further, pain was ranked as more aversive than low fear, $\underline{z}$ $=-5.63 ; \underline{p}<.001$.

As an additional method for understanding how the participants responded to the three different stimuli, a MANOVA was conducted for self-report ratings of aversiveness at the second time period (i.e., $30 \mathrm{~s})$. Because participants experienced the same level of pain in two separate trials, these two ratings were averaged. A significant main effect of aversiveness was indicated, Wilks $\lambda=.63, \underline{F}(2,45)=13.02, \underline{p}$ $<.001$. For the follow-up analyses, the Bonferroni-corrected $\alpha$ was set at $.05 / 3=.0167$. These tests indicated findings similar to those revealed for the aversiveness rankings of the three stimuli. Specifically, high fear $(\underline{M}=1.78$, S.D. $=2.04)$ was associated with higher aversiveness rating than either low fear $(\underline{M}=$ 0.68$, S.D. $=1.14)$ or pain $(\underline{M}=1.05$, S.D. $=1.33)$. Further, higher aversiveness was associated with pain than with low fear. Interestingly, ratings of distress and discomfort, which were also collected during the experimental procedure, showed a similar pattern of results, although some differences among these ratings did not reach statistical significance.

\section{Pre-Procedure Self-Report Instruments}

Table 4 presents descriptive data from the three self-report instruments (i.e., ASI, BDI-II, and FPQ-III) given to participants before the experimental procedure began. To better understand the relation between scores on the self -report measures and dependent variables from the present experiment, correlational analyses were performed. Dependent measures were collapsed across all four of the trials 
to provide average scores of distress. Table 5 displays the findings from the correlational analyses. For the most part, no relation between the self-report measures and dependent variables was indicated. The only two questionnaire scores related to any of the dependent measures were the Fear of Minor Pain subscale of the FPQ-III and the FPQ-III total score. Both were significantly related to verbal report of pain (for FPQ-III Minor Pain, $\underline{r}=.37, \underline{p}<.01$; for FPQ-III total score, $\underline{r}=.36, \underline{p}<.05$ ). Individuals with high scores on these scales had greater changes in their pain ratings over the course of the four trials. In order to follow-up these significant correlations, one stepwise regression equation were calculated for verbal report of pain, as this was the only dependent measure significantly correlated with questionnaire measures. Subscale scores from the ASI, FPQ-III, and the total score from the BDI were entered as predictor variables. Predictor variables that met criteria for entry (ㅁ to enter 0.05$)$ and did not subsequently meet criteria for removal (ㅁ to remove 0.10 ) were retained. The FPQ-III minor pain subscale score accounted for approximately $14 \%$ of the variance in pain ratings, $\exists=.37, \underline{p}<.01 ; \underline{r}^{2}=.14$.

\section{Coping Self-Report Measure}

Table 6 displays means and standard deviations for the coping questionnaire that was completed by each participant at the conclusion of the present experiment. Listed on the table are the questions posed to participants as well as the corresponding scales from the CSQ developed by Rosensteil \& Keefe (1983), after which the present questionnaire was modeled. With regard to the relation between coping and the dependent measures of the present study, bivariate correlations revealed that greater changes in verbal fear rating over all four trials was associated with greater using of the praying/hoping coping strategy $(\underline{r}=.34, \underline{p}<.05)$. Table 7 displays all correlations between the coping measure and dependent variables.

\section{Discussion}

The main goals of this study were to (a) more specifically and precisely define the relation between fear and pain, and (b) to clarify how these two states affect one another. To achieve these goals, fear stimulus intensity and presentation order of painful or fearful stimuli were manipulated with 48 healthy college undergraduates. Using a within-subjects design, four experimental trials were experienced by each of the participants and four measures of distress were assessed (i.e., escape time, heart rate, verbal report of 
fear, verbal report of pain). For all variables except escape time, three measurements across time were taken. The first measure was taken before each trial began and provided a pre-trial/baseline, the second measure, taken approximately $30 \mathrm{~s}$ into each trial, provided a manipulation check, and the third measure gave an indication of the overall effect of the manipulation.

\section{Principal Findings}

The main findings of the present study suggest that when faced with more than one aversive stimuli, individuals tend to respond preferentially to the stimulus that they perceive to be the worst. Furthermore, these results are noteworthy due to the significant amount of synchrony displayed among the three response modalities.

Across all included overt and physiological measures, and verbal reports of fear, the high fear level, which was rated by most participants as the most aversive stimulus, seemed to account for much of the variability in distress behavior, confirming our first hypothesis. Further, greater distress often occurred when the high level of fear was experienced as the first stimulus. Our second and third hypotheses, which stated that trials in which the painful stimulus was experienced first would be associated with the most distressed responding, were not confirmed. Instead, fear level affected all three modes of responding, with more "distressed" responding (i.e., lower tolerance times, higher heart rate changes, higher fear rating change) associated with the higher level of fear, especially when the high level of fear was encountered first as the single stimulus.

The finding that fear takes precedence over pain provides support for Bolles and Faneslow's (1980) PDR model of fear and pain. As hypothesized by the PDR model, in the present experiment, high fear inhibited pain responding. Specifically, higher levels of fear tended to occur with low levels of pain. Furthermore, other studies have found that fear tends to increase distress responding (Roy-Bryne \& Katon, 2000); however, no studies to date have found that the nature of fear's effect on distress is dependent on how aversive the fear is related to other stimuli.

Further support for the hypothesis that individuals preferentially respond to stimuli that are more aversive is found when findings concerning the painful stimulus are evaluated. Specifically, pain was rated as less aversive than the high fear stimulus and more aversive than the low fear stimulus by most 
participants. Significantly more pain was reported for the low level of fear compared to the high level, indicating that while high fear preferentially determined responding when it was present, pain determined responding in the presence of low fear. Although these results did not occur for pain ratings across measures of overt or physiological behavior, they do provide support for a model concerned with the importance of perceived aversiveness. This result is compatible with the findings of Eccleston and Crombez (1999), who argue that organisms are evolutionarily predisposed to pay attention to painful stimuli.

If one considers the findings detailed in the above two paragraphs, two separate, and up until now, incompatible, results are present. Namely, the above results indicate that fear takes precedence over pain and that pain takes precedence over fear, thus supporting two different models of the relation between fear and pain (i.e., Bolles \& Faneslow, 1980, \& Eccleston \& Crombez, 1999). The difference in the present findings, however, is that participants rated the degree to which each stimulus was aversive in relation to the other two. Therefore, these results are compatible with both models: fear takes precedence over pain when fear is perceived to be the worst stimulus in the environment and the reverse is true when pain is perceived to be the worst.

Eccleston and Crombez (1999) argue for a "resource-based" model of distress responding, where an individual's attention is given to the more aversive stimulus. The results of the present investigation are compatible in some ways with this model. As noted above, however, whereas Eccleston and Crombez conclude that pain is always the most aversive stimulus because of genetic and evolutionary factors, these results imply that distress responding is simply a function of the most aversive stimulus in one's environment. In the case of the Eccleston studies (Eccleston, 1995; Eccleston \& Crombez), pain was the more aversive stimulus, thus pain responding was elevated. With regard to the current project, high fear was rated as the more aversive stimulus, thus distress responding in this area was increased.

\section{Data Integrity}

For pre-trial measurements, no significant differences were seen among the different trials for the physiological and verbal measures. This absence of differences indicated that participants were in 
relatively similar states before beginning each of the four trials. Further, it underscored the effectiveness of the Latin Square procedure used to randomize the presentation of the four trials.

In terms of the manipulation check, the verbal ratings provided information regarding the effectiveness of the stimuli used in the present experiment to produce the desired response. For the first $30 \mathrm{~s}$ of each trial, participants were exposed to a single stimulus (i.e., pain, high fear, or low fear). When verbal ratings for this time period were analyzed, significant increases in pain ratings were observed when pain was experienced first. Similarly, increases in fear were observed for the high level of fear when it was experienced first. The only exception was for the low level of fear, which did not correspond with a change in fear level for this time period. Therefore, the manipulations used in the present experiment appeared to be effective for the most part, the only exception was the absence of any effect of the low level of fear.

Interestingly, when participants were exposed to only high fear stimulus, they rated their pain as significantly increased after 30 seconds, which was not expected. One could argue that this indicates that these individuals are rating their pain not solely on nocioceptive sensations, but also to some degree are giving a rating of overall distress or aversiveness. Looking at pain in this way is very much in accord with the IASP's (1994) definition of pain, but there is a dearth of literature investigating exactly how aversive, but non-tissue damaging, stimuli can increase an individual's perception of pain.

\section{$\underline{\text { Gender Effects }}$}

With regard to the effects of participant and experimenter gender, only a few patterns were apparent. Females exhibited more rapid escape times and reported higher fear levels, and males exhibited slower escape and lower reported fear levels. Further, when female participants were in the company of female experimenters, their fear ratings were typically higher than when they were with male experimenters, indicating that females may feel more comfortable reporting high levels of fear to individuals of the same gender. Similar complex effects of gender have been revealed in other experiments concerning emotion and pain (Carter et al., in press; Rollman, Lautenbacher, \& Jones, 2000); however, the findings in the present study differ somewhat with respect to specific findings. Although the effects of gender were controlled and specifically analyzed for in the present experiment, the 
large number of required post-hoc comparisons likely significantly increased the alpha level for these analyses, thus these results must be interpreted with caution. Future investigations into differences in pain and fear responding between the two genders may benefit from limiting other manipulations and looking only at gender differences in order to reduce the complexity of results and risk of committing type I errors.

\section{Participant Trait Effects}

A number of descriptive measures, which tapped into constructs relevant to fear and pain responding, were included in the present design. Although all of these measures have been found to have a reliable relation with fear or pain, previous findings were not replicated. Only the FPQ-III total score and Minor Pain subscale score had a relation with pain responding, and this relation was moderate in size. This lack of findings indicates that other variables may have influenced how participants responded to the painful and fearful stimuli. Hypotheses regarding the nature of these other variables may be forwarded with caution. First, the experimental manipulation of the two fear levels had a notable effect on participant responding, thus this manipulation may have been powerful enough to override individual differences tapped into by the self-report questionnaires. Second, some other participant characteristic, which was not measured, may have been a more important determinant of behavior. Finally, although the three constructs measured in the present study (e.g., anxiety sensitivity, depression, fear of pain) have an established record of influencing pain and fear responding, these previous studies have been primarily performed with clinical populations (e.g., chronic pain, dental/oral surgery), therefore these findings may not be entirely applicable to the present population. With regard to limitations, the range of scores on the self-report questionnaires were limited in two ways. First, for ethical reasons, we chose to exclude individuals who exhibited clinically significant amounts of anxiety sensitivity or depression, which added an artificial ceiling to scores on these two measures. Secondly, the population used in this study was composed primarily of young, healthy individuals who were not expected to show a significant amount of psychopathology. Both of these factors likely led to a reduction in the correlation between self-report measures and dependent measures, which typically occurs when the range of values is restricted (Howell, 1997). 
As with the other self-report measures, findings for the measure of coping used in the present study were somewhat disappointing. Praying or hoping that the aversive stimulus would end was the only strategy associated with some aspect of distress responding, and even this measure was only related to fear reports. The lack of findings may indicate that participants used other ways to cope with the aversive stimuli, or it may indicate that they used no formal coping strategy. Alternately, as noted in the preceding paragraph, the experimental manipulation may have been strong enough to obscure or take priority over the effects of using the different coping strategies. The use of an instrument with unknown psychometric properties may also have limited our ability to assess the coping strategies used by participants.

\section{Limitations}

The difficulty of inducing fear in a laboratory setting is well-established (Carter et al., in press; Sorrell et al, 2001; Vlaeyen \& Linton, 2000). The present experiment, however, sought to induce fear using an empirically-validated method, namely $\mathrm{CO}_{2}$-enriched air (Zvolensky \& Eifert, 2001), which was effective for the high level of fear (i.e., $15 \% \mathrm{CO}_{2}$ ), but not for the low level (i.e., $5 \% \mathrm{CO}_{2}$ ). The difficulty in inducing reliable levels of fear in the laboratory stem from a number of sources. First, fear is a multidimensional construct (McNeil, et al., 1994); therefore, a successful manipulation of fear must likely influence behavior at all of the three modes of responding. Secondly, all emotion induction took place in a contrived environment (i.e., the laboratory) and thus issues of external validity are raised. Finally, previous research has indicated that control over an aversive event, particularly control over the termination of the event, is associated with decreased distress responding (Zvolensky, Eifert, Lejuez, \& McNeil, 1999). Participants in most laboratory experiments, including the present one, generally have control over the termination of the experiment for ethical reasons and this may have decreased the effectiveness of the fear induction. Future studies would benefit from using significantly fearful stimuli (e.g, $15 \% \mathrm{CO}_{2}$ ), when inducing fear in the laboratory.

As noted in the above paragraph, the population used in the present study also limit the conclusiveness of the findings. These individuals were relatively young, mostly healthy, almost exclusively Caucasian, and were not as experienced with pain or fear as some clinical populations. Thus, 
it is possible that a clinical population would show a different pattern of responding to the stimuli used in this study.

Finally, it should be noted that a significant amount of research regarding the relation of fear and pain has been performed in the area of chronic pain. As noted elsewhere, the differences between acute and chronic pain go beyond the issue of simple duration (Gatchel \& Epker, 1999; Sanders, 1985). Specifically, chronic pain is typically associated with more disability and psychopathology. Therefore, the results of the present study, which was concerned with acute pain induced in a laboratory environment, may not be applicable to individuals with chronic pain in a clinical setting. However, compatible findings in the area of chronic pain are present. For example, significant fear of pain at times appears to take precedence over pain levels in determining both disability (Al-Obaidi, Nelson, Al-Awadhi, \& Al-Shuwaie, 2000) and treatment outcome (McCracken \& Gross, 1998; McCracken, Gross, \& Eccleston, in press) in individuals with chronic pain. These studies indicate that if significant fear is present, individuals will tend to respond to this fear over their response to pain. Once fear levels are diminished, the individual's level of disability typically also decreases, as do some aspects of psychopathology.

\section{$\underline{\text { Conclusions }}$}

In summary, results indicate that individuals tend to respond most robustly to the stimulus in the environment that they perceive to be the worst, or most aversive. Specifically, the high fear stimulus was rated by participants as the most aversive and caused the most distress, so this stimulus accounted for much of the variability in participant responding. In addition, the painful stimulus was ranked as the second most aversive stimulus and influenced behavior more than the low fear stimulus, which was ranked as least aversive. These findings have significant theoretical implications in a field concerned with the relation and interaction between fear and pain. Previous theoretical and experimental designs have argued that fear is preferentially attended to relative to pain (Bolles \& Faneslow, 1980), or that pain takes precedence over fear (Eccleston \& Crombez, 1999). The present findings imply that both of these approaches are correct - the nature of the relation between fear and pain depends on how aversive each stimulus is perceived to be in relation to the other. Therefore, neither pain nor fear always dictate the nature of the relation; it is dependent on current and past environmental factors (which influence current 
cognitions). Therefore, future studies and clinicians working with populations that present with significant levels of fear and pain may benefit from using the implications of this study. Specifically, when an individual is being exposed to a number of aversive stimuli, as is often the case in chronic pain and a number of other illnesses, particular attention should be paid to which aversive stimulus is perceived by the individual as the worst in his or her environment so that appropriate clinical interventions may be made. 


\section{References}

Al Absi, M. \& Rokke, P. D. (1991). Can anxiety help us tolerate pain? Pain, 46, 43-51.

Al-Obaidi, S. M., Nelson, R. M., Al-Awadhi, S., \& Al-Shuwaie, N. (2000). The role of anticipation and fear of pain in the persistence of avoidance behavior in patients with chronic low back pain. $\underline{\text { Spine, }}$ 25, $1126-1131$.

Arntz, A., \& De Jong, P. (1993). Anxiety, attention and pain. Journal of Psychosomatic Research, 37, 423-432.

Arntz, A., Dreessen, L., \& Merckelback, H. (1991). Attention, not anxiety, influences pain. Behaviour Research and Therapy, 29, 41-50.

Asmundson, G. J. G. (1999). Anxiety sensitivity and chronic pain: Empirical findings, clinical implications, and future directions. In Taylor, S. (Ed.). Anxiety sensitivity: Theory, research, and treatment of the fear of anxiety (pp. 269-285). Mahwah, N.J.: Erlbaum.

Asmundson, G. J. G., Walker, J. R., Furer, P., \& Kjernisted, K. (2000, March). Beyond anxiety: A preliminary look at acute and chronic pain in individuals seeking treatment for anxiety disorders. In C. Carmin \& D. Hope (chairs), Anxiety disorders and medical problems: Confounding and confusing issues in diagnosis and treatment. Symposium conducted at the $20^{\text {th }}$ annual meeting of the Anxiety Disorders Association of America, Washington DC.

Barlow, D. H. (1988). Anxiety and its disorders: The nature and treatment of anxiety and panic. New York: Guilford.

Barlow, D. H. (1991). Disorders of emotion. Psychological Inquiry, 2, 58-71.

Beck, A. T., Rush, A. J., Shaw, B. F., \& Emery, G. (1979). Cognitive therapy of depression. New York : Guilford.

Beck, A. T., Steer, R. A., \& Garbin, M. (1988). Psychometric properties of the Beck Depression Inventory: Twenty-five years of evaluation. Clinical Psychology Review, 8, 77-100.

Bengtson, A., Herlitz, J., Karlsson, T., \& Hjalmarson, A. (1996). Distress correlates with the degree of chest pain: A description of patients awaiting revascularisation. Heart, 75, 257-260. 
Bolles, R. C., \& Faneslow, M. S. (1980). A perceptual-defensive-recuperative model of fear and pain. The Behavioral and Brain Sciences, 3, 291-323.

Brown, G. K., \& Nicassio, P. M. (1987). Development of a questionnaire for the assessment of active and passive coping strategies in chronic pain patients. Pain, 31, 53-64.

Carter, L., McNeil, D. W., Vowles, K. E., Sorrell, J. T., Turk, C., \& Ries, B. (in press). Effects of emotion on pain reports, tolerance, and physiology. Journal of Pain and Symptom Management.

Cioffi, D., \& Holloway, J. (1993). Delayed costs of suppressed pain. Journal of Personality and Social Psychology, 64, 274-282.

Cook, E. W., III, Atkinson, L., \& Lang, K. G. (1987). Stimulus control and data acquisition for IBM PC's and compatibles. Psychophysiology, 24, 726-727. (Abstract)

Crombez, G., Vlaeyen, J. W. S., Heuts, P. H. T. G., \& Lysens, R. (1999). Pain related fear is more disabling than pain itself: Evidence on the role of pain -related fear in chronic back pain disability. Pain, 80, 329-339.

Dougher, M. J., Goldstein, D., \& Leight, K. A. (1987). Induced anxiety and pain. Journal of Anxiety Disorders, 1, 259-264.

Eccleston, C. (1995). Chronic pain and distraction: An experimental investigation into the role of sustained and shifting attention in the processing of chronic persistent pain. Behaviour Research and Therapy, 33, 391-405.

Eccleston, C., \& Crombez, G. (1999). Pain demands attention: A cognitive-affective model of the interruptive function of pain. Psychological Bulletin, 125, 356-366.

Fishbain, D. A., Cutler, R., Rosomoff, H. L., \& Rosomoff, R. S. (1997). Chronic pain-associated depression: Antecedent or consequence of chronic pain? A review. The Clinical Journal of Pain, 13, 116137.

Forgione, A. G. \& Barber, T. X. (1971). A strain gauge pain simulator. Psychophysiology, 8, 102106

Forsyth, J. P., Eifert, G. H., \& Thompson, R. N. (1996). Systemic alarms in fear conditioning II: An experimental methodology using $20 \% \mathrm{CO}_{2}$ inhalation as a USCS. Behavior Therapy, 27, 391-415. 
Gatchel, R. J., \& Epker, J. (1999). Psychosocial predictors of chronic pain and response to treatment. In R. J. Gatchel \& D. C. Turk (Eds.), Psychosocial factors in pain: Critical perspectives (pp. 412-434. New York: Guilford.

Green, S. B., Salkind, N. J., \& Akey, T. M. (2000). Using SPSS for windows: Analyzing and understanding data (2nd ed.). Upper Saddle River, NJ: Prentice Hall.

Hadjistavropoulos, H. D., \& Lachapelle, D. L. (2000). Extent and nature of anxiety experienced during physical examination of chronic low back pain. Behaviour Research and Therapy, 38, 13-29.

Harrington, P. J., Schmidt, N. B., \& Telch, M. J. (1996). Prospective evaluation of panic potentiation following $35 \% \mathrm{CO}_{2}$ challenge in nonclinical subjects. American Journal of Psychiatry, 153 , 823-825.

Howell, D. C. (1997). Statistical methods for psychology (4th ed.). Belmont, CA: Wadsworth. Hursey, K. G., \& Jacks, S. D. (1992). Fear of pain in recurrent headache sufferers. Headache, 32, 283-286.

International Association for the Study of Pain Task Force on Taxonomy. (1994). Classification of chronic pain: Descriptions of chronic pain syndromes and definitions of pain terms (2nd ed.; pp. 209-214). Seattle, WA: IASP Press.

Katon, W., Korff, M. V., Lin, E., Lipscomb, P., Russo, J., Wagner, E., \& Polk, E. (1990). Distress high utilizers of medical care. DSM-III-IR diagnoses and treatment needs. General Hospital Psychiatry, 12, 355-362.

Kessler, R., McGonagle, K., Zhao, S., Nelson, C., Hughes, M., Eshleman, S., Wittchen, H. U., \& Kendler, K. (1994). Lifetime and 12-month prevalence of DSM-III-R psychiatric disorder in the United States. Results from the National Comorbidity Study, Archives of General Psychiatry, 51, 8-19.

Krause, S. J., Weiner, R. L., \& Tait, R. C. (1994). Depression and pain behavior in patients with chronic pain. The Clinical Journal of Pain, 10, 122-127.

Lejuez, C. W., Forsyth, J. P., \& Eifert, G. H. (1998). Devices and methods for administering carbon dioxide-enriched air in experimental and clinical settings. Journal of Behavior Therapy and Experimental Psychiatry, 29, 239-248. 
Lejuez, C. W., O’Donnnell, J., Wirth, O., Zvolensky, M. J., \& Eifert, G. H. (1998). Avoidance of $20 \%$ carbon dioxide-enriched air with humans. Journal of the Experimental Analysis of Behavior, $70,79-$ 86.

Lethem, J., Slade, P. D., Troup, J. D. G., \& Bentley, G. (1983) Outline of a fear-avoidance model of exaggerated pain perception - I. Behaviour Research and Therapy, 21, 401-408.

Marcus, S., Olfson, M., Pincus, H., Shear, M., \& Zarin, D. (1997). Self-reported anxiety, general medical conditions, and disability bed days. American Journal of Psychiatry, 154, 1766-1768.

McCracken, L. M. (1997). Attention to pain in persons with chronic pain: A behavioral approach. Behavior Therapy, 28, 271-284.

McCracken, L. M., Faber, S. D., \& Janeck, A. S. (1998). Pain-related anxiety predicts non-specific physical complaints in persons with chronic pain. Behaviour Research and Therapy, 36, 621-630.

McCracken, L. M., \& Gross, R. T. (1993). Does anxiety affect coping with chronic pain? The Clinical Journal of Pain, 9, 253-259.

McCracken L. M., \& Gross, R. T. (1998). The role of pain-related anxiety reduction in the outcome of multidisciplinary treatment for chronic low back pain: Preliminary results. Journal of Occupational Rehabilitation, 8, 179-189.

McCracken, L. M. Gross, R. T. \& Eccleston, C. (in press). Multimethod assessment of treatment process in chronic low back pain: Comparison of reported pain-related anxiety with directly measured physical capacity. Behaviour Research and Therapy.

McGrath, P. A. (1994). Psychological aspects of pain perception. Archives of Oral Biology, 39, Supplement, 55S-62S.

McNally, R. J. (1996). Anxiety sensitivity is distinguishable from trait anxiety. In R. M. Rapee (Ed.), Current controversies in the anxiety disorders (pp. 214-227). New York: Guilford.

McNeil, D. W., \& Rainwater, A. J. (1998). Development of the Fear of Pain Questionnaire-III. Journal of Behavioral Medicine, 21, 389-410.

McNeil, D. W., Turk, C. L., \& Ries, B. J. (1994). Anxiety and fear. Encyclopedia of human behavior, Volume 1, 151-163. 
Melzack, R. \& Wall, P. D. (1965). Pain mechanisms: A new theory. Science, 150, 971-979.

Melzack, R., \& Wall, P. D. (1982). The challenge of pain. New York: Basic Books.

Nelson, F. V., Zimmerman, L., Barnason, S., Nieveen, J., \& Schmaderer, M. (1998). The relationship and influence of anxiety on postoperative pain in the coronary artery bypass graft patient. Journal of Pain and Symptom Management, 15, 102-109.

Rainwater, A. J. \& McNeil, D. W. (1991). Reinventing the algometer: Synopsis of the literature and presentation of a reliable, inexpensive model. Behavior Research Methods, Instruments, and Computers, 23, 486-492.

Reiss, S., Peterson, R. A., Gursky, D. M., \& McNally, R. J. (1986). Anxiety sensitivity, anxiety frequency, and the prediction of fearfulness. Behaviour Research and Therapy, 24, 1-8.

Rethelyi, J. M., Berghammer, R., \& Kopp, M. S. (2001). Comorbidity of pain-associated disability and depressive symptoms in connection with sociodemographic variables: Results from a cross-sectional epidemiological survey in Hungary. Pain, 93, 115-121.

Rhudy, J., \& Meagher, M. (2000) Fear and anxiety: Divergent effects on human pain thresholds, Pain, 84, 65-75.

Rollman, G. B., Lautenbacher, S., \& Jones, K. S. (2000) Sex and gender differences in responses to experimentally induced pain in humans. In R. B. Fillingim (Ed.) Sex, gender, and pain: Vol. 17. Progress in pain research and management (pp. 165-190). Seattle, WA.: IASP Press.

Rosensteil, A. K., \& Keffe, F. J. (1983). The use of coping strategies in chronic low back pain patients: Relationship to patient characteristics and current adjustments. Pain, 14, 33-34.

Roy-Byrne, P. P., \& Katon, W. (2000). Anxiety management in the medical setting: rationale, barriers to diagnosis and treatment, and proposed solutions. In D. I. Mostofsky \& D. H. Barlow (Eds.), The management of stress and anxiety in medical disorders (pp. 1-14). Needham Heights, MA: Allyn \& Bacon.

Sanders, S. H. (1985). Chronic pain: Conceptualization and epidemiology. Annals of Behavioral Medicine, 7, 3-5.

Sanderson, W. C., \& Wetzler, S. (1990) Five percent carbon dioxide challenge: Valid analogue and marker of panic disorder? Biological Psychiatry, 27, 689-701. 
Simon, G. (1992). Psychiatric disorder and functional somatic symptoms as predictors of health care use. Psychiatric Medicine, 10, 49-59.

Schmidt, N. B., \& Cook, J. H. (1999). Effects of anxiety sensitivity on anxiety and pain during a cold pressor challenge in patients with panic disorder. Behaviour Research and Therapy, 37, 313-323.

Schmidt, N. B., \& Telch, M. J. (1997). Nonpsychiatric medical comorbidity, health perceptions, and treatment outcome in patients with panic disorder. Health Psychology, 16, 114-122.

Snow-Turek, A. L., Norris, M. P., \& Tan, G. (1996). Active and passive coping strategies in chronic pain patients. Pain, 64, 455-462.

Sorrell, J. T., McNeil, D. W., Vowles, K. E., Broadman, L. M., Hursey, K. G., Huber, S. J., Vaglienti, R. M., \& Kennedy, S. G. (2001, March). Effects of pain and fear stimulus intensity on pain responding in chronic pain patients. Poster presented at the meeting of the Society of Behavioral Medicine, Seattle, WA.

Sperry-Clark, J. A., McNeil, D. W., \& Ciano-Federoff, L. (1999). Assessing chronic pain patients: The Fear of Pain Questionnaire-III. In L. VandeCreek \& T. L. Jackson (Eds.), Innovations in clinical practice: A source book (vol. 17, pp. 293-305). Sarasota, FL: Professional Resource Press.

Spinhoven, P., \& Lissen, A. C. (1991). Behavioral treatment of chronic low back pain. I. Relation of coping strategy use to outcome. Pain, 45, 29-34.

Staats, P. S., Hekmat, H., \& Staats, A. W. (1996). The psychological behaviorism theory of pain. Pain Forum, 5, 194-207.

Stein, M. B., Jang, K. L., \& Livesley, W. J. (1999). Heritability of anxiety sensitivity: A twin study. American Journal of Psychiatry, 156, 246-251.

Suinn, R. M. (2001). The terrible twos - anger and anxiety: Hazardous to your health. American Psychologist, 56, 27-36.

Tabachnick, B. G., \& Fidell, L. S. (2001) Using multivariate statistics (4th ed.). Needham Heights, MA: Allyn \& Bacon. 
Tarnowski, K. J., Brown, R. T., Dingle, A. D., \& Dreelin, E. (1998). Pain management. In R. T. Ammerman \& J. V. Campo (Eds.), Handbook of pediatric psychology and psychiatry (pp. 1-15). Needham Heights, MA: Allyn \& Bacon.

Thomas, V. J., Heath, M. L., \& Rose, F. D. (1990). Effect of psychological variables and pain relief system on postoperative pain experience. British Journal of Anesthesia, 27, 388-389.

Vlaeyen, J. W., \& Linton, S. J. (2000). Fear-avoidance and its consequences in chronic musculoskeletal pain: A state of the art. Pain, 85, 317-332.

Vassend, O. (1993). Anxiety, pain, and discomfort associated with dental treatment. Behaviour Research and Therapy, 31, 659-666.

Weinfurt, K. P. (1995). Multivariate analysis of variance. In L. G. Grimm, \& P. R. Yarnold (Eds.). Reading and understanding multivariate statistics (pp. 245-276). Washington, D. C.: American Psychological Association.

Weinstein, J. (1991). Neurogenic and nonneurogenic pain and inflamatory mediators. Orthopedic Clinics of North America, 22, 235-246.

Weisenberg, M., Aviram, O., Wolf, Y., \& Raphaeli, N. (1984). Relevant and irrelevant anxiety in the reaction to pain. Pain, 20, 371-383.

Wolpe, J. (1958). Psychotherapy by reciprocal inhibition. Stanford, CA: Stanford University Press. Zelman, D. C., Howland, E. W., Nichols, S. N., \& Cleeland, C. S. (1991). The effects of induced mood on laboratory pain. Pain, 46, 105-111.

Zvolensky, M. J., \& Eifert, G. H. (2001). A review of psychological factors/processes affecting anxious responding during voluntary hyperventilations and inhalations of carbon dioxide-enriched air. Clinical Psychology Review, 21, 375-400.

Zvolensky, M. J., Eifert, G. H., Lejuez, C. W., \& McNeil, D. W. (1999). The effects of offset control over $20 \%$ carbon dioxide-enriched air on anxious responding. Journal of Abnormal Psychology, 108, 624632. 
Zvolensky, M. J., Goodie, J. L., McNeil, D. W., Sperry, J. S., \& Sorrell, J. T. (2001). Anxiety sensitivity in the prediction of pain-related fear and anxiety in a heterogeneous chronic pain population. Behaviour Research and Therapy, 39, 683-696. 


\section{Appendix A}

\section{$\underline{\text { Response to Stimuli Questionnaire }}$}

INSTRUCTIONS: Please indicate the degree to which you engaged in the following behaviors while you were experiencing any discomfort associated with your involvement in this study (e.g., pressure weight, carbon dioxide-enriched air).

1. How much did you attempt to distract yourself from the discomfort by thinking about or paying attention to other things?

$\begin{array}{lllllll}\text { I } & \text { I } & \text { I } & \text { I } & \text { I } & \text { I } & \text { I } \\ \text { 0 } & \mathbf{1} & \mathbf{2} & \mathbf{3} & \mathbf{4} & \mathbf{5} & \text { I }\end{array}$

Never

All the time

2. How much did you attempt to imagine that you were somewhere else where you would not feel the discomfort?

$\begin{array}{lllllll}\text { I } & \text { I } & \text { I } & \text { I } & \text { I } & \text { I } & \text { I } \\ \text { 0 } & \mathbf{1} & \mathbf{2} & \mathbf{3} & \mathbf{4} & \mathbf{5} & \mathbf{6}\end{array}$

Never $\quad$ All the time

3. How much did you say to yourself that you could cope with the discomfort?

$\begin{array}{lllllll}\text { I } & \text { I } & \text { I } & \text { I } & \text { I } & \text { I } & \text { I } \\ \text { I } & \mathbf{1} & \mathbf{2} & \mathbf{3} & \mathbf{4} & \mathbf{5} & \mathbf{6}\end{array}$

Never All the time

4. How much did you ignore the discomfort?

$\begin{array}{lllllll}\text { I } & \text { I } & \text { I } & \text { I } & \text { I } & \text { I } & \text { I } \\ \text { I } & \mathbf{1} & \mathbf{2} & \mathbf{3} & \mathbf{4} & \mathbf{5} & \mathbf{6} \\ \text { Never } & & & & & & \text { All the time }\end{array}$

5. How much did you pray or hope that the discomfort would subside?

$\begin{array}{lllllll}\text { I } & \text { I } & \text { I } & \text { I } & \text { I } & \text { I } & \text { I } \\ \text { I } & \mathbf{1} & \mathbf{2} & \mathbf{3} & \mathbf{4} & \mathbf{5} & \mathbf{6} \\ \text { Never } & & & & & & \text { All the time }\end{array}$

6. How much did you think about the severity of the discomfort?

$\begin{array}{lllllll}\mathrm{I} & \mathrm{I} & \mathrm{I} & \mathrm{I} & \mathrm{I} & \mathrm{I} & \mathrm{I} \\ \mathrm{I} & \mathbf{1} & \mathbf{2} & \mathbf{3} & \mathbf{4} & \mathbf{5} & \mathbf{6}\end{array}$

Never $\quad$ All the time 


\section{Appendix A (con't)}

7. How much did you move other parts of you body to distract yourself from the discomfort?

$\begin{array}{lllllll}\text { I } & \text { I } & \text { I } & \text { I } & \text { I } & \text { I } & \text { I } \\ \text { I } & \mathbf{1} & \mathbf{2} & \mathbf{3} & \mathbf{4} & \mathbf{5} & \mathbf{6} \\ \text { Never } & & & & & & \text { All the time }\end{array}$

8. How much did you perform actions to reduce your pain?

$\begin{array}{lllllll}\text { I } & \text { I } & \text { I } & \text { I } & \text { I } & \text { I } & \text { I } \\ \text { I } & \mathbf{1} & \mathbf{2} & \mathbf{3} & \mathbf{4} & \mathbf{5} & \mathbf{6} \\ \text { Never } & & & & & & \text { All the time }\end{array}$


Appendix B

\section{Consent and Information Form}

\section{Order Effects of Pain and Fear Induction}

Introduction. I,

have been invited to participate in this research study that has been explained to me by Kevin E. Vowles or an associate or assistant of his choosing. This research is being conducted by Kevin E. Vowles, B.A. and Daniel McNeil, Ph.D. to fulfill requirements for Mr. Vowles' master's thesis in clinical psychology at West Virginia University.

Purposes of the Study. I understand that the purpose of this study is to identify how pain, fear, and their order of presentation influence behavioral response, emotions, and thoughts.

Description of Procedures. I will be one of 72 undergraduate students who will participate in this study. I understand that the study involves only one session that will last approximately 90 minutes. This session will take place in the Anxiety, Psychophysiology, and Pain Laboratory (room 306) located in Oglebay Hall. My participation in this research will involve filling out six brief questionnaires, five before the experimental procedure and one after. I may see all of the questionnaires before signing this consent form and I do not have to answer any questionnaires or questions that I find objectionable.

I understand that sensors will be taped to my chest and side to record heart rate throughout the study. I understand that at different times during the procedure, I will place one of my fingers in an "algometer" pressure device, which I will be allowed to see and will be demonstrated to me before I consent. The algometer is an apparatus made of wood and plastic that is used to produce a mounting pressure on the finger placed in the device. My hand will rest on a wooden platform while the stimulated finger rests on the same platform between two smaller pieces of wood. Resting on top of the stimulated finger is a blunt plastic wedge with a small wooden platform attached to the top of the plastic. When this portion of the device is in place, various weights can be set on top of the platform to produce different degrees of pressure at the site of the finger where the plastic wedge is located. This device produces a building discomfort and temporary pain, but causes no lasting damage or lasting pain.

Furthermore, I understand that throughout the session, I will be wearing a breathing mask over my mouth and nose, and I will breathe either normal room air or room air which is mixed with higher-than-normal concentrations of carbon dioxide (5\% carbon dioxide, $21 \%$ oxygen, and $74 \%$ nitrogen or $15 \%$ carbon dioxide, $21 \%$ oxygen, and $64 \%$ nitrogen) for up to five minutes. I understand that I may take off the mask at any time I wish, whether I am experiencing any effects of the gas or not. My heart rate will be monitored continuously by a trained research assistant throughout the procedure using electrodes that will be attached to my skin with adhesive tape. Specifically, heart rate will be monitored by placing two electrodes on my upper chest and one on a lower rib cage. Also, I understand I will be monitored by the experimenter observing me throughout the study. The researcher will stop the procedure if I choose to do so, or if there are indications of significant adverse effects.

Finally, I understand that throughout the experimental procedure, the experimenter will ask me to record my level of fear, panic, anxiety, pain, discomfort, distress, and aversiveness on sheets of paper that are provided to me.

Risks and Discomforts. There are no known or expected risks from participation in this study. Temporary discomfort is expected when I am exposed to painful pressure stimulation with a weight on four of my fingers. The sensations I may experience when exposed to this stimulation is similar to a 
Appendix B (con't)

progressively painful, pinching, and building pressure. These sensations are expected to disappear quickly when the stimulation is discontinued. In addition, discomfort may be experienced at those times when breathing room air which is mixed with higher-than-normal concentrations of carbon dioxide. The effects of breathing carbon dioxide-enriched room air may include racing heart sensations, increased breathing rate, shortness of breath, and dizziness. These effects are harmless and are expected to disappear quickly when returning to breathing normal room air.

I understand that I may discontinue my participation at any time.

Financial Considerations. There are no special fees for participating and I understand that I will receive $\$ 10$ or class extra credit following my participation in the present study.

Alternatives. I understand that I am not required to participate in this study. Although I may receive extra credit in my psychology course for my participation, I realize that there are other ways to earn extra credit. Another alternative that I have is to not participate.

Benefits. Possible benefits that I may gain by participating in this study include the knowledge of experimentation procedures and the functioning of a psychological laboratory and knowledge that my participation may benefit others.

Voluntary Compensation. If injury occurs as a result of this research, treatment will be available. No compensation will be voluntarily provided by the investigator, West Virginia University, or other associated organizations and corporations.

Contact Persons. In the event I experience any side effects related to this research, or for more information about it, I should contact Kevin E. Vowles, B.A. at 293-2001 (ext. 805), or his supervisor, Daniel W. McNeil, Ph.D. at 293-2001 (ext. 622). For information regarding my rights as a research participant, I may contact the Executive Secretary of the Institutional Review Board at 293-7073.

Confidentiality. I understand that any information about me obtained, as a result of my participation in this research, will be kept as confidential as legally possible. I also understand that my research records, just like hospital records, may be subpoenaed by a court order or may be inspected by federal regulatory authorities. In any publication that results from this research, neither my name nor any information from which I might be identified will be published without my consent.

Voluntary Participation. Participation in this study is voluntary. I understand that I am free to withdraw my consent to participate in this study at any time. Refusal to participate or withdrawal will involve no penalty or loss of benefits and will not affect my class standing or grades in any way. I have been given the opportunity to ask questions about the research, and I have received answers concerning areas I did not understand. Upon signing this form, I will receive a copy.

I willingly consent to participate in this study.

Signature of Participant

Signature of Investigator or Investigator's Representative
Date

Date 


\section{Appendix C}

\section{$\underline{\text { Standardized Instructional Set }}$}

\section{Pre-Experiment Instructions}

\section{Explanation and instructions for pre-trial heartrate measurement.}

"In order to use your heart rate as an indicator of the amount of physiological arousal you are experiencing, we must obtain a resting baseline with which to compare. In this study, we want to obtain five different readings of your heart rate: The first prior to beginning the procedure and the next four after each condition in the study."

\section{Relaxation instructions.}

"During the collection of this data, it is very important that you relax as much as possible. Sit comfortably in the chair with your feet flat on the floor in front of you. Let your hands rest comfortably on the arms of the chair. The relaxation period will last approximately 5 minutes for each physiological recording period. At the end of each relaxation period I will have a set of instructions for you to follow. What questions do you have at this point?"

\section{General directions.}

"As discussed in the consent form you just read, you will be exposed to both carbon-dioxide enriched air and pressure stimulation via the Algometer device at various times during this procedure. At times, you will only experience one of these stimuli and at other times, you will experience both.

Although you are free to discontinue participation at any time, it would be extremely helpful if you can endure any arousal you may experience until you hear the triple tone. After that point, please do your best to finish the condition, which will be a maximum of five minutes long. If at any point you become too uncomfortable to continue, please remember that you are permitted to stop at any time by placing your hand on the red "Stop" sign in front of you.

Throughout the study, I will ask you several times to tell me your current level of fear, panic, anxiety, pain, discomfort, distress, and aversiveness. When you make these ratings, please use this scale in front of you (demonstrate scale). It goes from 0 to 9 , where $0=$ No feelings of fear, panic, anxiety, etc. and 9 = Maximum possible fear, panic, anxiety, etc. you have ever experienced. You are to circle the appropriate number on the scale on these sheets of paper. When making your ratings, please rate what you are experiencing at that specific instance and only as it is related to the task you are doing at that moment. For example, when rating the pain you are experiencing or are about to experience, rate only the pain in the finger that you are feeling related to the experiment.

\section{Do you have any questions?"}

\section{Pre-trial standardized instructions.}

In this trial, you will receive the (pressure, $15 \% \mathrm{CO}_{2}, 5 \% \mathrm{CO}_{2}$ ) for the first 30 seconds, and the (pressure, $15 \% \mathrm{CO}_{2}, 5 \% \mathrm{CO}_{2}$ ) during the last $4 \frac{1 / 2}{2}$ minutes. You will hear a single tone at the beginning, at the 30 second-mark, and at the end of the trial. If you begin to feel too uncomfortable, touch the stop sign in front of you to discontinue the trial. Please attempt to remain in each condition at least until you hear the triple tone at 60 seconds. 


\section{Appendix D}

\section{Procedural Flow Chart}

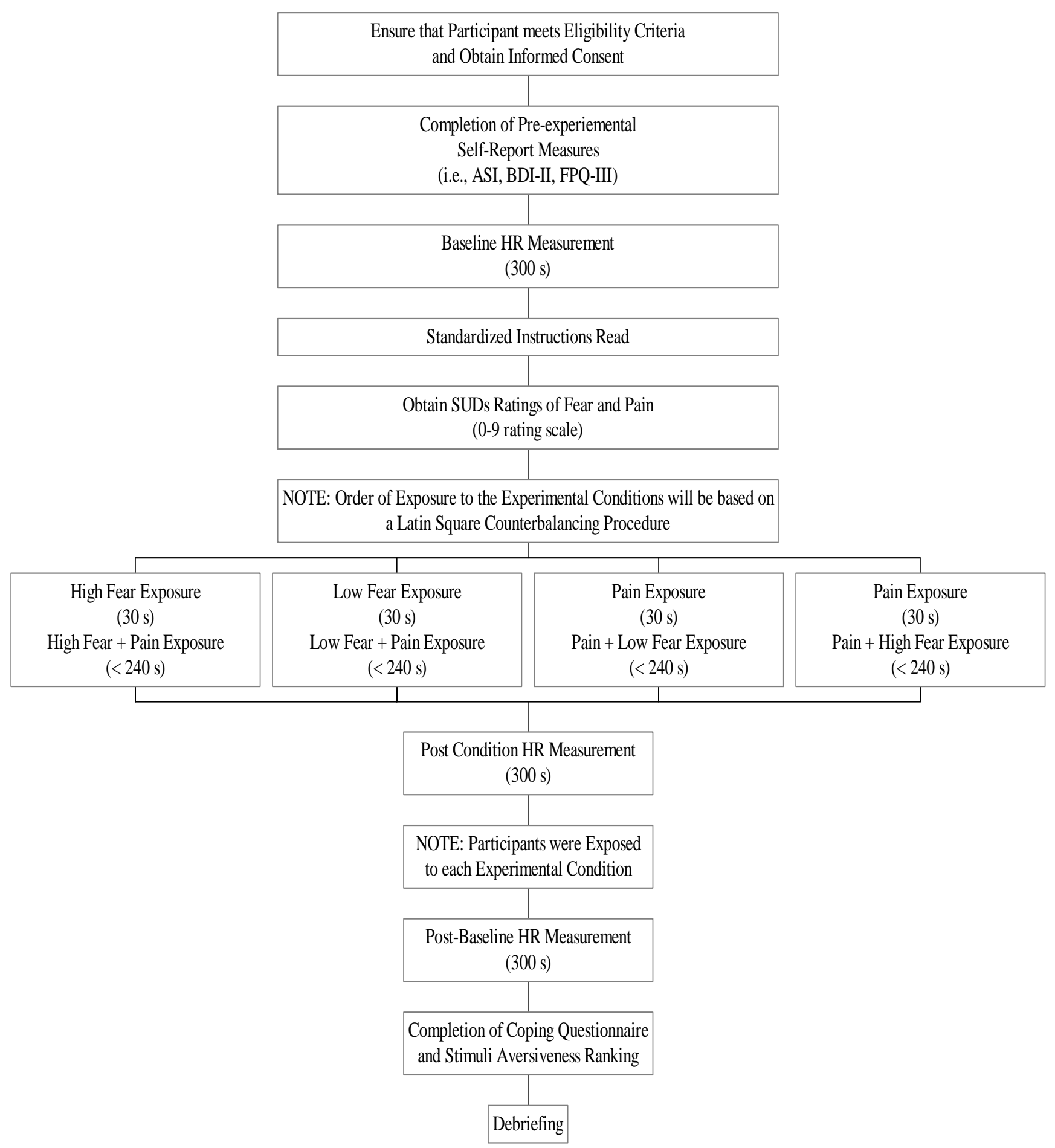




\begin{tabular}{|c|c|c|c|c|}
\hline \multicolumn{5}{|c|}{ Appendix E } \\
\hline \multicolumn{5}{|c|}{ MANOVA Table for Escape Time } \\
\hline Effects & $\underline{\text { Wilks } \lambda}$ & $\underline{\mathrm{df}}$ & $\underline{F}$ & $\underline{\mathrm{p}}$ \\
\hline $\mathrm{F} \times \mathrm{O}$ & .96 & 2 & 2.18 & .15 \\
\hline $\mathrm{O}$ & .25 & 1 & .31 & .58 \\
\hline $\mathrm{F}$ & .99 & 1 & 144.86 & $<.001$ \\
\hline
\end{tabular}

Note. $\mathrm{F}=$ Fear level; $\mathrm{O}=$ Stimulus presentation order 


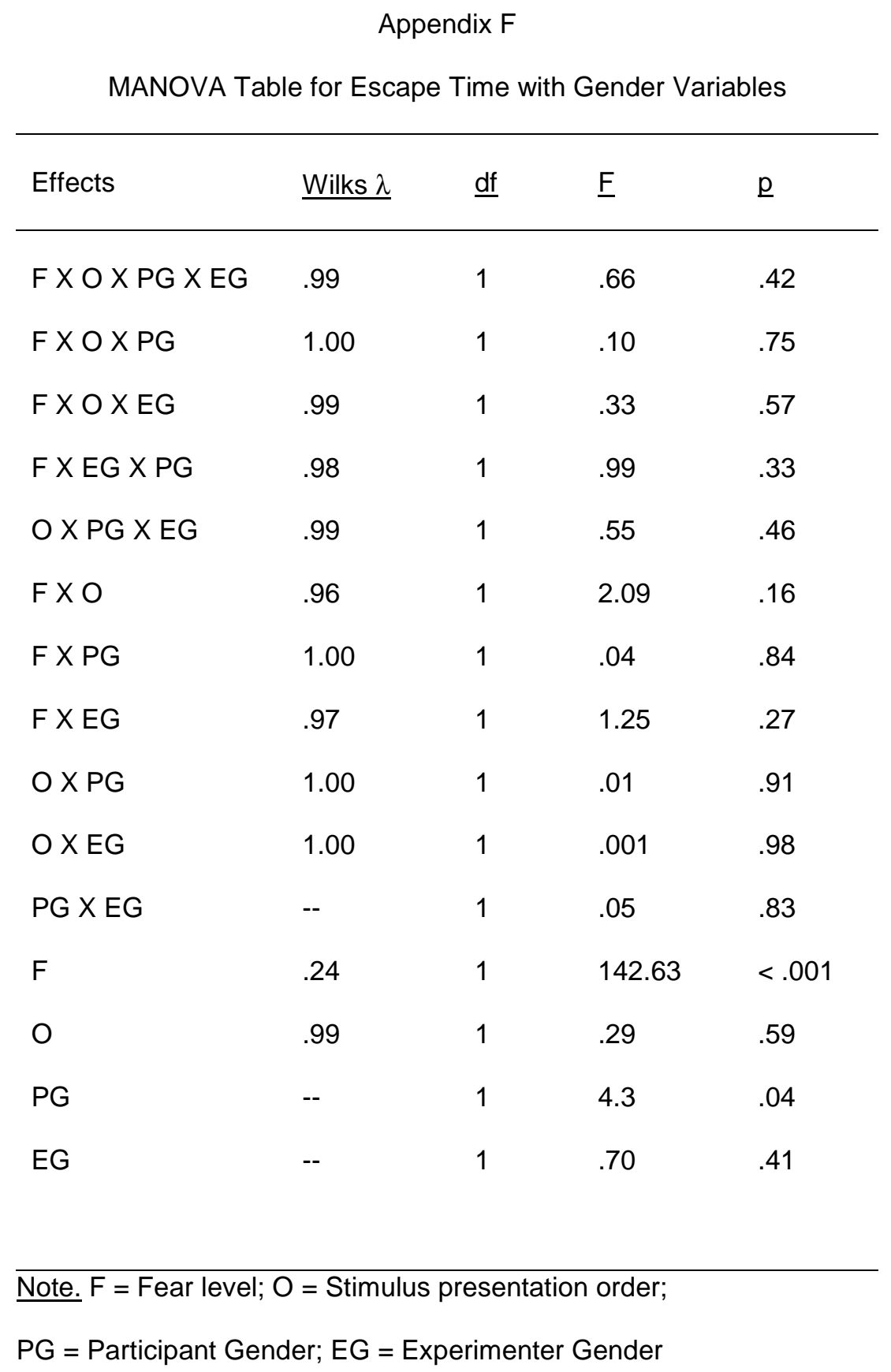


Appendix $G$

MANOVA Table for Heart Rate

\begin{tabular}{lllll}
\hline$\underline{\text { Effects }}$ & $\underline{\text { Wilks } \lambda}$ & $\underline{\mathrm{df}}$ & $\underline{\mathrm{F}}$ & $\underline{\mathrm{p}}$ \\
\hline $\mathrm{F} \times \mathrm{O} \times \mathrm{T}$ & .72 & 2 & 8.79 & .001 \\
$\mathrm{~F} \times \mathrm{O}$ & .88 & 1 & 6.49 & .01 \\
$\mathrm{~F} \times \mathrm{T}$ & .51 & 2 & 22.44 & $<.001$ \\
$\mathrm{OXT}$ & .61 & 2 & 14.99 & $<.001$ \\
$\mathrm{~F}$ & .65 & 1 & 25.09 & $<.001$ \\
$\mathrm{O}$ & .88 & 1 & 6.55 & .01 \\
$\mathrm{~T}$ & .29 & 2 & 57.33 & $<.001$
\end{tabular}

Note. $\mathrm{F}=$ Fear level; $\mathrm{O}=$ Stimulus presentation order; $\mathrm{T}=$ Time segment 
Appendix $\mathrm{H}$

MANOVA Table for Heart Rate with Gender Variables

\begin{tabular}{|c|c|c|c|c|}
\hline Effects & Wilks $\lambda$ & $\underline{\mathrm{df}}$ & $\underline{F}$ & $\underline{p}$ \\
\hline$F \times O X T \times P G \times E G$ & .99 & 2 & .15 & .86 \\
\hline$F \times O X T \times P G$ & .96 & 2 & 1.02 & .37 \\
\hline FXOXTXEG & .97 & 2 & .59 & .56 \\
\hline$F \times O X P G \times E G$ & .98 & 1 & 1.07 & .31 \\
\hline$F \times T \times P G \times E G$ & .87 & 2 & 3.09 & .06 \\
\hline$O \times T \times P G \times E G$ & .90 & 2 & 2.43 & .10 \\
\hline$F \times O X P G$ & .98 & 1 & .95 & .34 \\
\hline FXOXEG & 1.00 & 1 & .16 & .70 \\
\hline $\mathrm{F} X O \mathrm{XT}$ & .72 & 2 & 8.51 & .001 \\
\hline$F \times E G \times P G$ & .92 & 1 & 3.89 & .06 \\
\hline FXTXPG & .94 & 2 & 1.33 & .28 \\
\hline FXTXEG & .99 & 2 & .29 & .75 \\
\hline$O \times P G \times E G$ & 1.00 & 1 & .04 & .85 \\
\hline OXTXPG & .89 & 2 & 2.68 & .08 \\
\hline OXTXEG & .97 & 2 & .78 & .46 \\
\hline$T \times P G \times E G$ & .87 & 2 & 3.28 & .06 \\
\hline $\mathrm{F} \times \mathrm{O}$ & .87 & 1 & 6.38 & .02 \\
\hline $\mathrm{F} \times \mathrm{T}$ & .47 & 2 & 24.49 & $<.001$ \\
\hline$F \times P G$ & 1.00 & 1 & .12 & .73 \\
\hline$F \times E G$ & 1.00 & 1 & .20 & .66 \\
\hline$O \times P G$ & 1.00 & 1 & .24 & .63 \\
\hline
\end{tabular}




\begin{tabular}{lllll}
\multicolumn{5}{l}{ Appendix H (con't) } \\
\hline OX EG & .93 & 1 & .33 & .57 \\
OX T & .60 & 2 & 14.10 & $<.001$ \\
TX PG & .95 & 2 & 1.12 & .34 \\
T X EG & .96 & 2 & 1.02 & .37 \\
PG X EG & -- & 1 & .50 & .48 \\
F & .63 & 1 & 25.74 & $<.001$ \\
O & .88 & 1 & 6.21 & .02 \\
T & .25 & 2 & 65.29 & $<.001$ \\
PG & -- & 1 & 1.76 & .19 \\
EG & -- & 1 & .26 & .61
\end{tabular}

Note. $\mathrm{F}=$ Fear level; $\mathrm{O}=$ Stimulus presentation order; $\mathrm{T}=$ Time segment; $P G=$ Participant Gender EG = Experimenter Gender 


\begin{tabular}{|c|c|c|c|c|}
\hline Effects & $\underline{\text { Wilks } \lambda}$ & $\underline{d f}$ & $\underline{F}$ & $\underline{p}$ \\
\hline $\mathrm{F} X O \mathrm{XT}$ & .79 & 2 & 6.55 & .003 \\
\hline $\mathrm{F} \times \mathrm{O}$ & .83 & 1 & 9.44 & .004 \\
\hline $\mathrm{F} \times \mathrm{T}$ & .41 & 2 & 32.85 & $<.001$ \\
\hline $\mathrm{OXT}$ & .87 & 2 & 3.43 & .04 \\
\hline $\mathrm{F}$ & .50 & 1 & 47.72 & $<.001$ \\
\hline $\mathrm{O}$ & .87 & 1 & 6.95 & .01 \\
\hline $\mathrm{T}$ & .40 & 2 & 34.89 & $<.001$ \\
\hline
\end{tabular}

Note. $\mathrm{F}=$ Fear level; $\mathrm{O}=$ Stimulus presentation order; $\mathrm{T}=$ Time segment 


\section{Appendix $\mathrm{J}$}

MANOVA Table for Fear Ratings with Gender Variables

\begin{tabular}{|c|c|c|c|c|}
\hline Effects & $\underline{\text { Wilks } \lambda}$ & $\underline{\mathrm{df}}$ & $\underline{F}$ & $\underline{\mathrm{p}}$ \\
\hline FXOXTXPG X EG & .82 & 2 & 4.81 & .01 \\
\hline $\mathrm{F} \times O \times T \times P G$ & .97 & 2 & .70 & .50 \\
\hline FXOXTXEG & .81 & 2 & 5.06 & .01 \\
\hline$F \times O X P G \times E G$ & 1.00 & 1 & .04 & .85 \\
\hline$F \times T \times P G \times E G$ & .96 & 2 & .98 & .38 \\
\hline$O \times T \times P G \times E G$ & .80 & 2 & 5.23 & .01 \\
\hline$F \times O X P G$ & .99 & 1 & .61 & .44 \\
\hline$F \times O X E G$ & 1.00 & 1 & .04 & .85 \\
\hline$F \times E G \times P G$ & 1.00 & 1 & .23 & .64 \\
\hline $\mathrm{F} \times \mathrm{O} \times \mathrm{T}$ & .76 & 2 & 6.93 & .002 \\
\hline $\mathrm{F} \times \mathrm{T} \times \mathrm{PG}$ & .99 & 2 & .22 & .81 \\
\hline FXTXEG & .92 & 2 & 1.94 & .16 \\
\hline$O \times P G \times E G$ & 1.00 & 1 & .12 & .74 \\
\hline$O \times T \times P G$ & .96 & 2 & .88 & .42 \\
\hline$O \times T \times E G$ & .94 & 2 & 1.44 & .25 \\
\hline$T \times P G \times E G$ & .90 & 2 & 2.53 & .09 \\
\hline $\mathrm{F} \times \mathrm{O}$ & .83 & 1 & 8.98 & .004 \\
\hline $\mathrm{F} \times \mathrm{T}$ & .40 & 2 & 31.78 & $<.001$ \\
\hline$F \times P G$ & .98 & 1 & .91 & .34 \\
\hline$F \times E G$ & .99 & 1 & .34 & .56 \\
\hline$O \times P G$ & .99 & 1 & .66 & .42 \\
\hline
\end{tabular}




\begin{tabular}{lllll}
\multicolumn{5}{l}{ Appendix J (con’t) } \\
\hline OX EG & 1.00 & 1 & .12 & .74 \\
OX T & .86 & 2 & 3.60 & .04 \\
TX PG & .95 & 2 & 1.09 & .35 \\
TX EG & .97 & 2 & .71 & .50 \\
PGX EG & -- & 1 & 4.45 & .041 \\
F & .49 & 1 & 46.18 & $<.001$ \\
O & .87 & 1 & 6.64 & .01 \\
T & .38 & 2 & 34.78 & $<.001$ \\
PG & -- & 1 & .001 & .97 \\
EG & -- & 1 & 1.80 & .19
\end{tabular}

Note. F = Fear level; $\mathrm{O}=$ Stimulus presentation order; $\mathrm{T}=$ Time segment; $P G=$ Participant Gender $; E G=$ Experimenter Gender 


\begin{tabular}{|c|c|c|c|c|}
\hline Effects & $\underline{\text { Wilks } \lambda}$ & $\underline{\mathrm{df}}$ & $\underline{F}$ & $\underline{\mathrm{p}}$ \\
\hline $\mathrm{FXOXT}$ & .75 & 2 & 7.61 & .001 \\
\hline $\mathrm{F} \times \mathrm{O}$ & .99 & 1 & .45 & .51 \\
\hline $\mathrm{F} \times \mathrm{T}$ & .59 & 2 & 15.86 & $<.001$ \\
\hline$O \times T$ & .41 & 2 & 32.70 & $<.001$ \\
\hline $\mathrm{F}$ & .78 & 1 & 13.07 & .001 \\
\hline O & .51 & 1 & 45.31 & $<.001$ \\
\hline $\mathrm{T}$ & .17 & 2 & 113.37 & $<.001$ \\
\hline
\end{tabular}

Note. $\mathrm{F}=$ Fear level; $\mathrm{O}=$ Stimulus presentation order; $\mathrm{T}=$ Time segment 
Appendix L

MANOVA Table for Pain Ratings with Gender Variables

\begin{tabular}{|c|c|c|c|c|}
\hline Effects & $\underline{\text { Wilks } \lambda}$ & $\underline{\mathrm{df}}$ & $\underline{F}$ & $\underline{\mathrm{p}}$ \\
\hline$F \times O X T X P G \times E G$ & .98 & 2 & .41 & .67 \\
\hline $\mathrm{F} \times O \times T \times P G$ & .96 & 2 & .91 & .41 \\
\hline FXOXTXEG & .92 & 2 & 1.96 & .15 \\
\hline$F \times O \times P G \times E G$ & .96 & 1 & 1.72 & .20 \\
\hline$F \times T \times P G \times E G$ & .99 & 2 & .18 & .84 \\
\hline$O \times T \times P G \times E G$ & .94 & 2 & 1.26 & .29 \\
\hline$F \times O X P G$ & .99 & 1 & .69 & .41 \\
\hline$F \times O X E G$ & .98 & 1 & .89 & .35 \\
\hline $\mathrm{F} \times \mathrm{O} \times \mathrm{T}$ & .74 & 2 & 7.61 & .001 \\
\hline$F \times E G \times P G$ & 1.00 & 1 & .02 & .88 \\
\hline$F \times T \times P G$ & .99 & 2 & .34 & .72 \\
\hline FXTXEG & .96 & 2 & .95 & .40 \\
\hline$O \times P G \times E G$ & 1.00 & 1 & .1 & .75 \\
\hline$O \times T \times P G$ & .97 & 2 & .79 & .46 \\
\hline$O \times T \times E G$ & .96 & 2 & .83 & .44 \\
\hline$T \times P G \times E G$ & .97 & 2 & .74 & .49 \\
\hline $\mathrm{F} \times \mathrm{O}$ & .99 & 1 & .45 & .51 \\
\hline $\mathrm{F} \times \mathrm{T}$ & .58 & 2 & 15.77 & $<.001$ \\
\hline$F \times P G$ & 1.00 & 1 & .20 & .65 \\
\hline$F \times E G$ & .99 & 1 & .40 & .53 \\
\hline$O \times P G$ & 1.00 & 1 & .07 & .80 \\
\hline
\end{tabular}




\begin{tabular}{lllll}
\multicolumn{5}{c}{ Appendix L (con't) } \\
\hline O X EG & 1.00 & 1 & .01 & .93 \\
OX T & .39 & 2 & 33.15 & $<.001$ \\
T X PG & .98 & 2 & .43 & .65 \\
T X EG & .93 & 2 & 1.57 & .22 \\
PG X EG & -- & 1 & 1.06 & .31 \\
F & .78 & 1 & 12.41 & .001 \\
O & .51 & 1 & 42.59 & $<.001$ \\
T & .16 & 2 & 109.24 & $<.001$ \\
PG & -- & 1 & .49 & .49 \\
EG & -- & 1 & .12 & .73 \\
& \\
\hline Note. F = Fear level; O = Stimulus presentation order; T = Time segment; \\
PG = Participant Gender; EG = Experimenter Gender
\end{tabular}


Table 1

Participant Demographics

Variable Total Number/Mean

24

24

19.8

13.9

Education (years)

Ethnicity

Caucasian

African-American

Asian-American

Hispanic

Marital status

Single

Live-in partner
43

$|89.6 \%|$

2

2

1

46

|95.8\% |

2

$\mid 4.2 \%$

$|4.2 \%|$

|2.1\%|

$|4.2 \%|$
Percentage//Standard

Deviation

$|50 \%|$

|50\% |

1.4

1.1 
Table 2

Mean and (Standard Deviation) Values for all Three Modes of Responding by Condition at each $\underline{\text { Time Period }}$

Condition

Mode of Responding $\begin{gathered}\text { Time } \\ \text { Segment }\end{gathered} \quad H F=>P+H F \quad L F=>P+L F \quad P=>P+H F \quad P=>P+L F$

Overt Behavior

$\begin{array}{llllll}\text { Escape Time (sec) } & \text { N/A } \quad 190.52(74.90) & 36.21(70.62) & 177.10(76.85) & 41.88(83.22)\end{array}$

Physiological

Heart Rate (bpm)

$\begin{array}{lllll}\text { Pre-trial } & 73.96(12.86) & 75.13(12.12) & 75.44(12.47) & 75.40(12.17) \\ 30 \mathrm{~s} & 82.61(12.08) & 78.00(11.70) & 77.88(12.62) & 77.53(13.10) \\ 60 \mathrm{~s} & 89.59(12.62) & 80.44(11.77) & 84.03(12.06) & 80.39(12.54)\end{array}$

Verbal Reports

Fear (0-9 scale)

$\begin{array}{lllll}\text { Pre-trial } & 1.13(1.54) & 0.96(1.43) & 0.92(1.32) & 0.94(1.71) \\ 30 \mathrm{~s} & 1.65(1.98) & 0.79(1.89) & 0.79(1.25) & 0.92(1.61) \\ \text { Post-Trial } & 4.06(2.62) & 1.46(1.89) & 3.38(2.54) & 1.52(1.82)\end{array}$

Pain (0-9 scale)

$\begin{array}{lllll}\text { Pre-trial } & 0.17(0.52) & 0.10(0.31) & 0.13(0.39) & 0.15(0.74) \\ 30 \mathrm{~s} & 0.73(1.62) & 0.23(0.56) & 2.06(1.44) & 2.13(1.78) \\ \text { Post-Trial } & 2.54(2.09) & 4.58(2.49) & 3.88(2.22) & 4.75(2.31)\end{array}$

Note. $\underline{N}=48$. 
Table 3

Descriptive Data for Aversiveness Ratings of High Fear, Low Fear, and Pain.

Stimulus

\begin{tabular}{llll} 
Aversiveness Ranking & $\underline{\text { High Fear }}$ & $\underline{\text { Low Fear }}$ & $\underline{\text { Pain }}$ \\
\hline Worst & $87.5 \%(\underline{\mathrm{N}}=42)$ & -- & $12.5 \%(\underline{\mathrm{N}}=6)$ \\
Second Worst & $12.5 \%(\underline{\mathrm{N}}=6)$ & $10.4 \%(\underline{\mathrm{N}}=5)$ & $77.1 \%(\underline{\mathrm{N}}=37)$ \\
Third Worst & -- & $91.7 \%(\underline{\mathrm{N}}=31)$ & $8.3 \%(\underline{\mathrm{N}}=4)$ \\
\hline Mean (S.D.) ranking from & $1.13(.33)$ & $2.91(.28)$ & $1.96(.46)$ \\
\multicolumn{2}{r}{ most to least aversive } & &
\end{tabular}


Table 4

Mean Scores and Standard Deviations (SD) for the Three Pre-Experiment Self-Report Measures

Measure

$\underline{\text { Scale }}$

Mean and (S.D.)

Anxiety Sensitivity Index

$\begin{array}{ll}\text { Physical } & 9.9(4.7) \\ \text { Psychological } & 2.4(2.7) \\ \text { Social } & 5.2(1.7) \\ \text { Total } & 14.8(6.5)\end{array}$

Beck Depression Inventory

Total

$7.4(4.4)$

Fear of Pain Questionnaire-III

Minor
Severe
Medical
Total

$17.9(6.7)$

$33.3(11.4)$

$23.3(7.0)$

74.5 (21.2)

Note. $\underline{N}=48$. 
Table 5

Correlations Among Dependent Variables and Self-Report Measures

\begin{tabular}{|c|c|c|c|c|c|c|c|c|c|c|c|c|c|}
\hline Measure & 1 & 2 & 3 & 4 & 5 & 6 & 7 & 8 & 9 & 10 & 11 & 12 & 13 \\
\hline 1. Escape Time & -- & -.08 & -.02 & .24 & .06 & .07 & -.04 & .05 & .14 & .27 & .16 & .16 & .22 \\
\hline 2. Heart Rate & & -- & .18 & .09 & -.22 & -.10 & -.08 & -.21 & .01 & -.12 & -.06 & -.10 & -.10 \\
\hline 3. Fear Rating & & & -- & $.49^{* *}$ & .11 & -.05 & .09 & .06 & -.04 & .17 & .16 & .15 & .19 \\
\hline 4. Pain Rating & & & & -- & .06 & .06 & -.08 & .04 & .03 & $.37^{* *}$ & .28 & .28 & $.36^{*}$ \\
\hline $\begin{array}{l}\text { 5. ASI- } \\
\text { Physical }\end{array}$ & & & & & -- & $.48^{\star *}$ & .15 & $.92^{* *}$ & .18 & $.46^{\star *}$ & $.45^{\star \star}$ & $.52^{\star *}$ & $.56^{\star *}$ \\
\hline $\begin{array}{l}\text { 6. ASI - } \\
\text { Psychological }\end{array}$ & & & & & & -- & -.02 & $.77^{\star \star}$ & $.47^{\star \star}$ & $.40^{\star *}$ & .22 & $.36^{*}$ & $.36^{*}$ \\
\hline $\begin{array}{l}\text { 7. ASI - } \\
\text { Social }\end{array}$ & & & & & & & -- & .24 & .02 & .03 & .11 & -.01 & .07 \\
\hline $\begin{array}{l}\text { 8. ASI - } \\
\text { Total Score }\end{array}$ & & & & & & & & -- & $.32^{\star \star}$ & $.48^{\star \star}$ & $.41^{\star \star}$ & $.51^{* *}$ & $.54^{\star \star}$ \\
\hline $\begin{array}{l}\text { 9. BDI-II - } \\
\text { Total Score }\end{array}$ & & & & & & & & & -- & $.29^{*}$ & -.04 & .18 & .13 \\
\hline $\begin{array}{l}\text { 10. FPQ-III - } \\
\text { Minor Pain }\end{array}$ & & & & & & & & & & -- & $.47^{\star \star}$ & $.79^{\star *}$ & $.83^{* *}$ \\
\hline $\begin{array}{l}\text { 11. FPQ-III - } \\
\text { Severe Pain }\end{array}$ & & & & & & & & & & & -- & $.50^{\star \star}$ & $.85^{\star \star}$ \\
\hline $\begin{array}{l}\text { 12. FPQ III - } \\
\text { Medical Pain }\end{array}$ & & & & & & & & & & & & -- & $.85^{\star \star}$ \\
\hline $\begin{array}{l}\text { 13. FPQ III - } \\
\text { Total Score }\end{array}$ & & & & & & & & & & & & & -- \\
\hline
\end{tabular}

* $\underline{p}<.05$

** $\underline{p}<.01$ 
Table 6

Mean and (Standard Deviation) Values for Coping Questionnaire

Item from Coping Questionnaire

How much did you:
Corresponding Scale from Rosensteil \& Keefe (1983)

Attempt to distract yourself from the discomfort by thinking about or paying attention to other things?

Attempt to imagine that you were somewhere else where you would not feel the discomfort?

Say to yourself that you could cope with the discomfort?

Ignore the discomfort?

Pray or hope that the discomfort would subside?

Think about the severity of the discomfort?

Move other parts of your body to distract yourself from the discomfort?

Perform actions to reduce your pain?
Diverting Attention

$4.13(1.42)$

Reinterpreting Pain Sensations

Coping Self Statements

Ignoring Pain Sensations

Praying/Hoping

Catastrophizing

Increasing Activity Level

Increasing Pain Behaviors

Note. $\underline{N}=48$. 
Table 7

Correlations Among Dependent Variables and Coping Measure

\begin{tabular}{|c|c|c|c|c|c|c|c|c|c|c|c|c|}
\hline Measure & 1 & 2 & 3 & 4 & 5 & 6 & 7 & 8 & 9 & 10 & 11 & 12 \\
\hline 1. Escape Time & -- & -.08 & -.02 & .24 & .17 & .03 & -.08 & -.17 & .12 & .05 & .21 & .06 \\
\hline 2. Heart Rate & & -- & .18 & .09 & -.07 & .01 & -.05 & -.19 & -.08 & .01 & .01 & .16 \\
\hline 3. Verbal Report of Fear & & & -- & $.49^{* *}$ & -.01 & .07 & .11 & -.16 & $.34^{*}$ & .18 & -.05 & .13 \\
\hline 4. Verbal Report of Pain & & & & -- & .24 & .14 & .18 & -.11 & .22 & .13 & .13 & .18 \\
\hline 5. Diverting Attention & & & & & -- & $.43^{* *}$ & $.31^{*}$ & .18 & $.34^{*}$ & $.38^{* *}$ & $.32^{*}$ & .10 \\
\hline 6. Reinterpreting Pain Sensations & & & & & & -- & .28 & .18 & .28 & .22 & $.31^{*}$ & .20 \\
\hline 7. Coping Self Statements & & & & & & & -- & .15 & $.40^{\star *}$ & .23 & .08 & -.05 \\
\hline 8. Ignoring Pain Sensations & & & & & & & & -- & -.05 & .12 & -.18 & .05 \\
\hline 9. Praying/Hoping & & & & & & & & & -- & $.30^{*}$ & .26 & .18 \\
\hline 10. Catastrophizing & & & & & & & & & & -- & .18 & $.33^{*}$ \\
\hline 11. Increasing Activity Level & & & & & & & & & & & -- & $.51^{* *}$ \\
\hline 12. Increasing Pain Behaviors & & & & & & & & & & & & -- \\
\hline
\end{tabular}

* $\underline{p}<.05$

** $\underline{p}<.01$ 


\section{Figure Captions}

Figure 1. Summary of each trial across time.

Figure 2. Mean escape time for each of the trials.

Figure 3. Heart rate for each trial across the three time segments.

Figure 4. Verbal fear ratings for each trial across the three time segments.

Figure 5. Verbal pain ratings for each trial across the three time segments. 


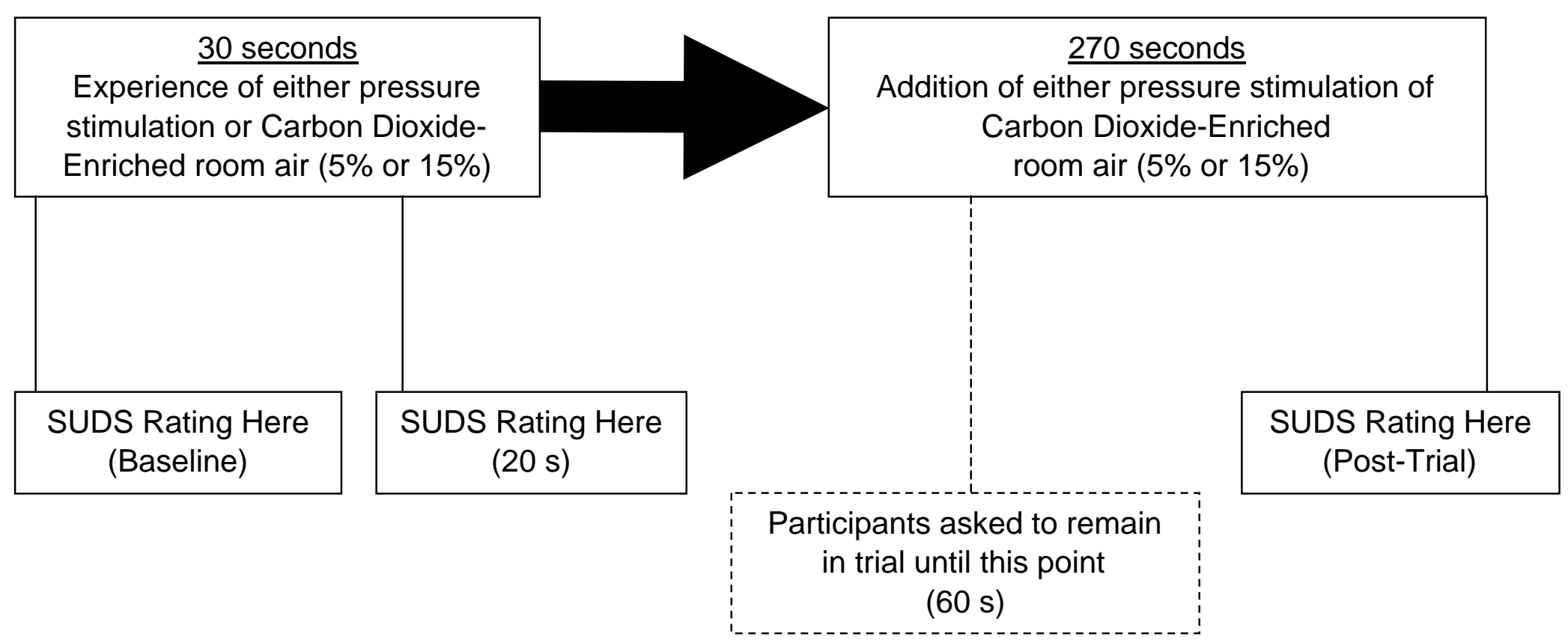




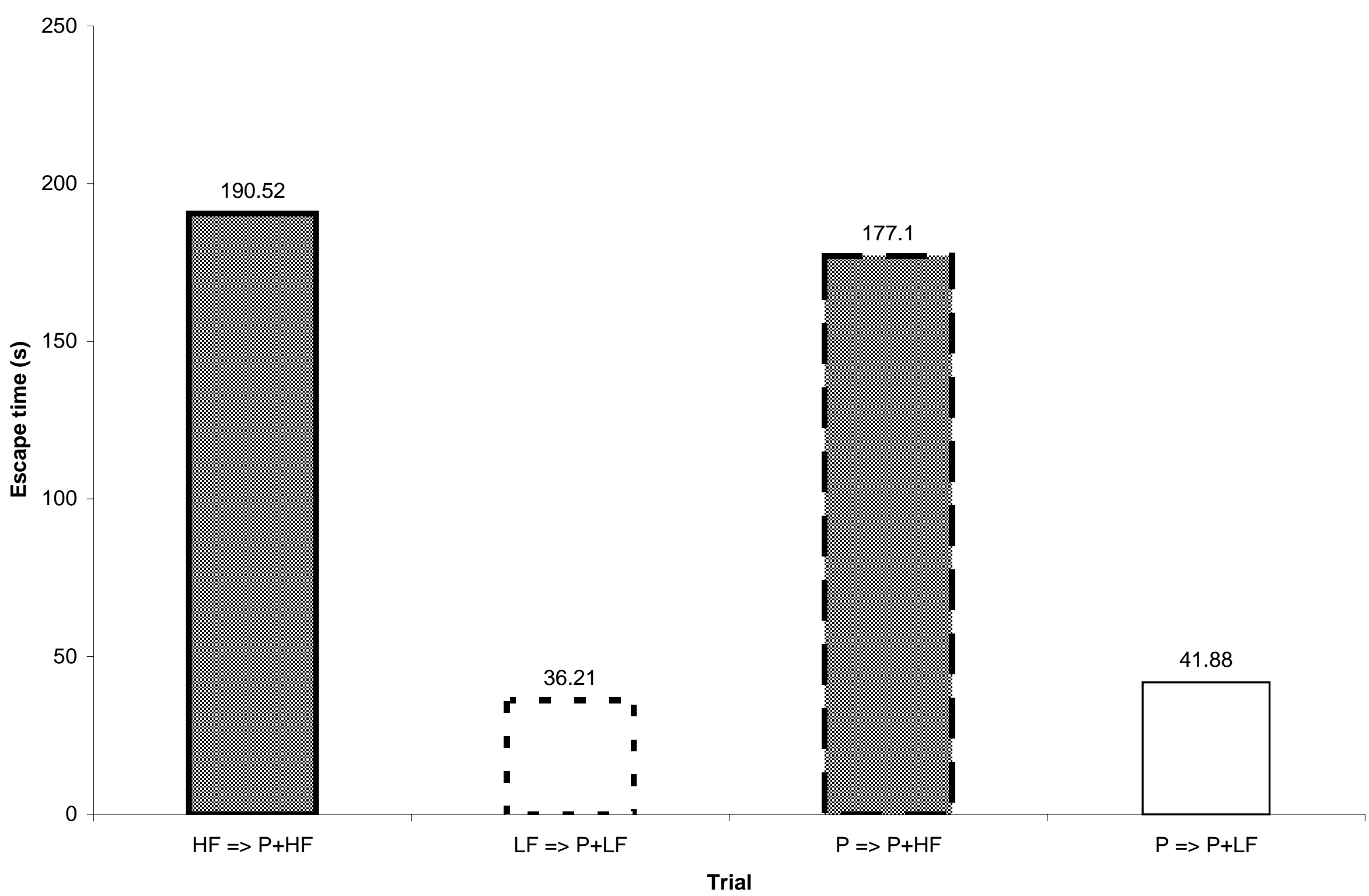




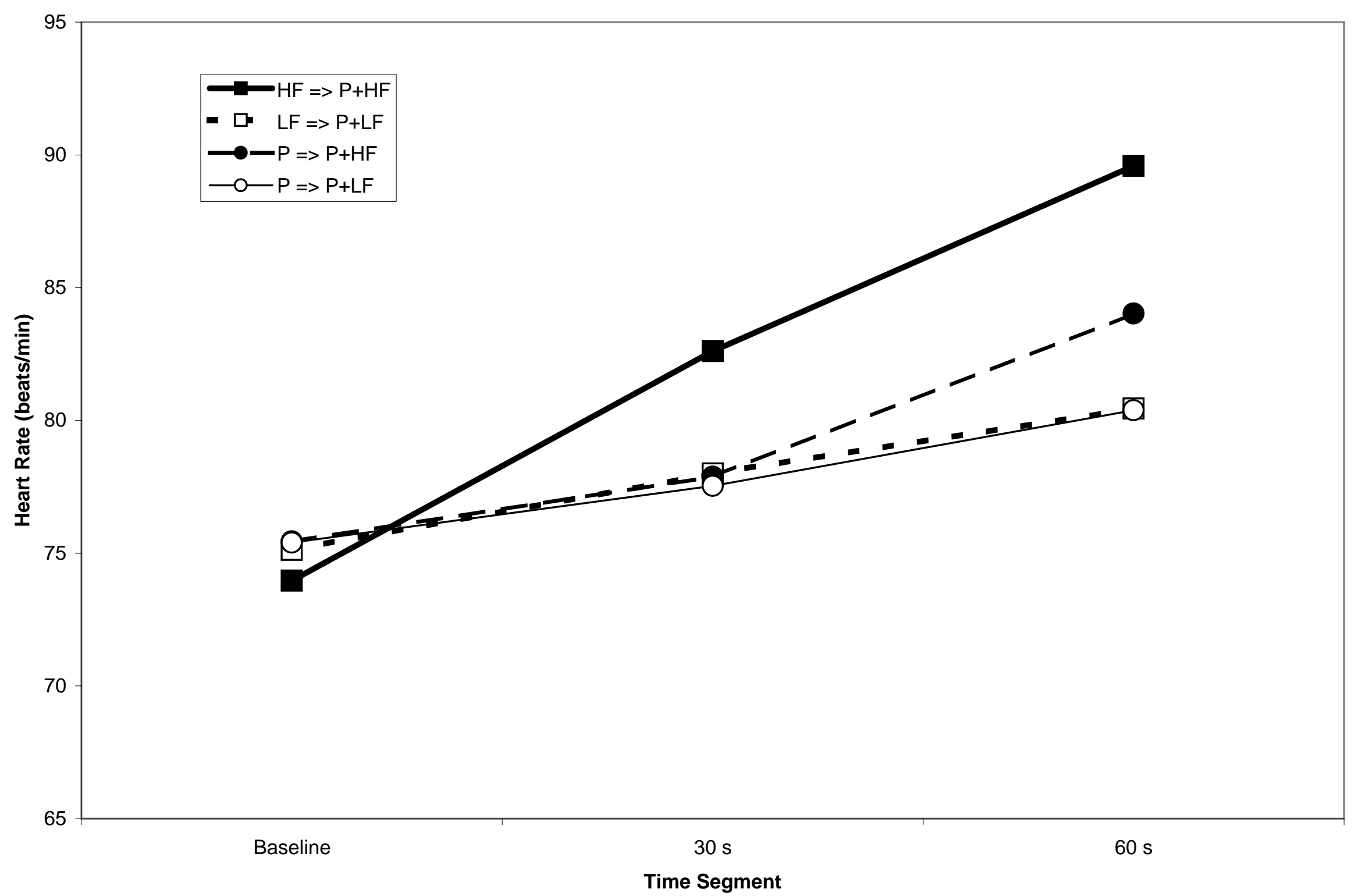




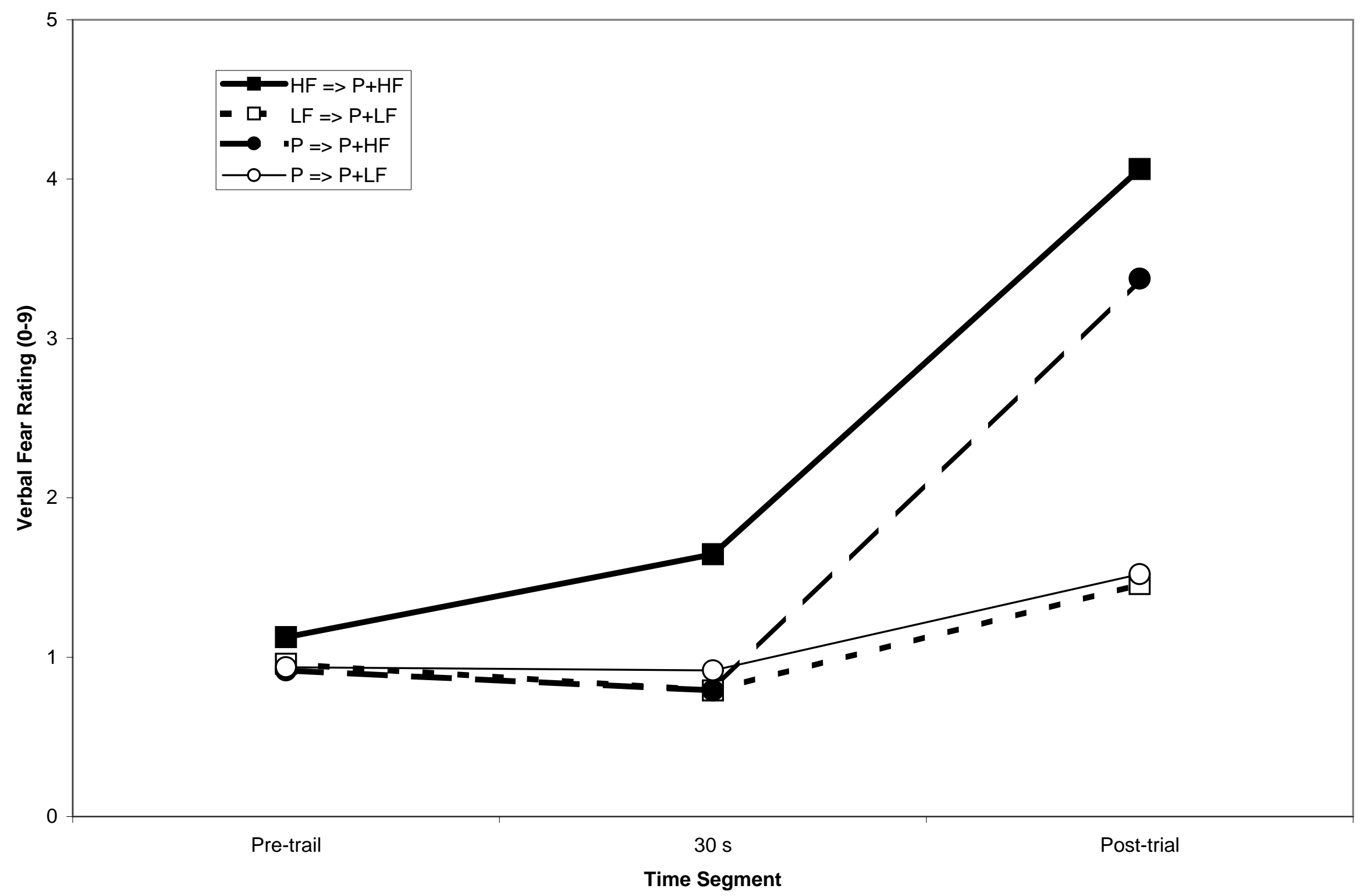




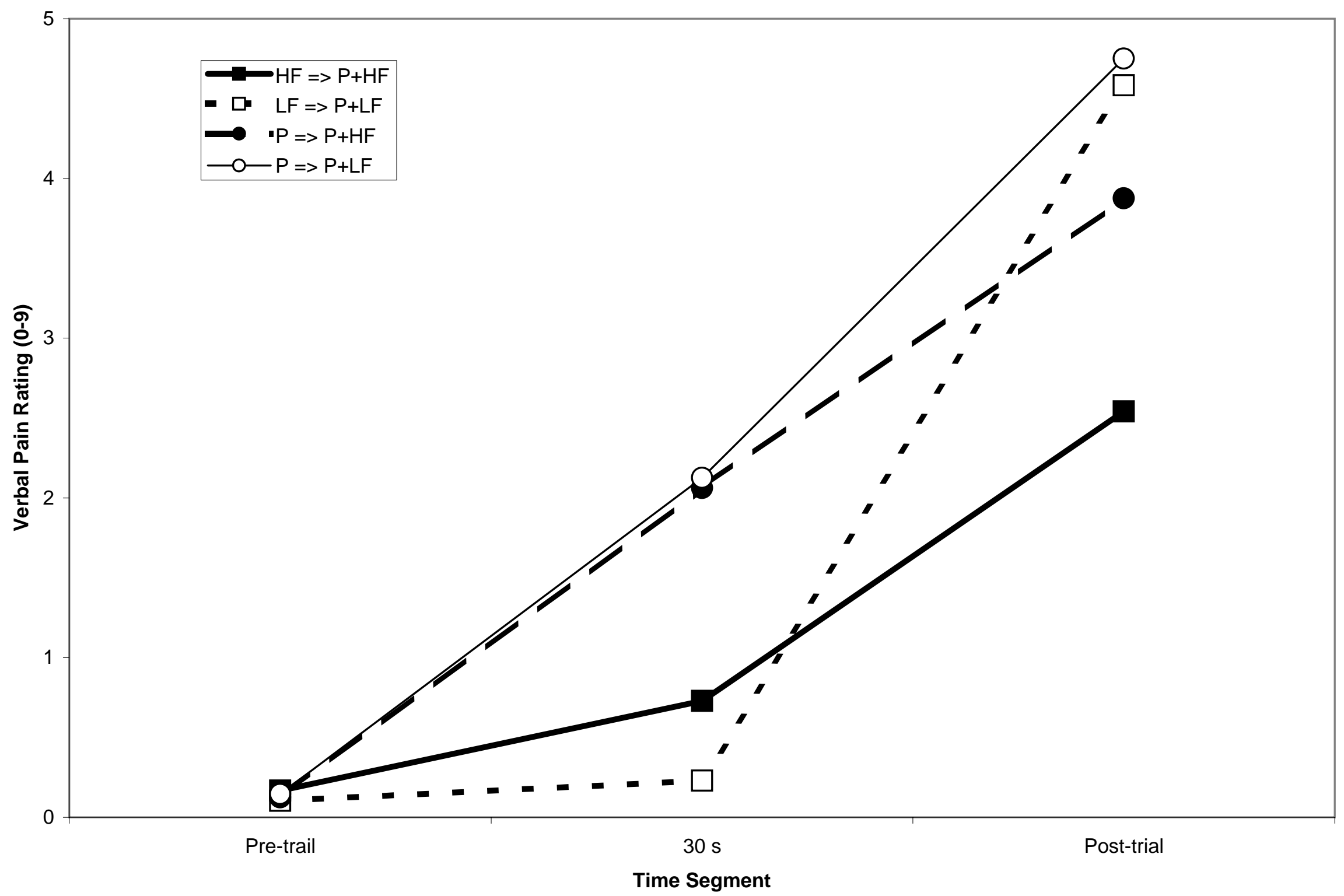


VITA

\section{Kevin Erik Vowles}

December 2001

\section{Office}

108 Oglebay Annex, Department of Psychology

West Virginia University

P.O. Box 6040

Morgantown, West Virginia 26506-6040

304-293-2001 x805 (Office)

304-293-6606 (FAX)

k_vowles@hotmail.com (e-mail)

\section{Home}

925 Ridgeway Ave.

Morgantown, West Virginia 26505

304-296-1661

\section{Educational Experiences}

Master of Arts in Psychology

West Virginia University

Morgantown, West Virginia

Degree expected: December 2001

Bachelor of Arts in Psychology

The University of Colorado at Boulder

Boulder, Colorado

Degree completed: December 1997

\section{Personal Data}

Date of Birth: April 3, 1974

Place of Birth: Reno, Nevada

Citizenship: United States of America

\section{Student Memberships}

American Psychological Association (APA)

APA Division 12 (Clinical Psychology)

APA Division 38 (Health Psychology)

Association for the Advancement of Behavior Therapy

Society of Behavioral Medicine 


\section{Research Activity}

\section{Articles, Chapters, Reviews, and Manuals (arranged chronologically)}

Joseph, K. E., Vowles, K. E., McNeil, D. W. (2000). Watch where you walk: An appeal for humane internship interviewing and other application processes. Association of Psychology Postdoctoral and Internship Centers Newsletter: The Journal of Training, 25, 9, 31-33.

Carter, L., McNeil, D. W., Vowles, K. E., Sorrell, J. T., Turk, C., \& Ries, B. (in press). Effects of emotion on pain reports, tolerance, and physiology, Pain Research and Management.

McNeil, D. W., Sorrell, J. T., Vowles, K. E., \& Lejuez, C. W. (in press). Social phobia. In M. Hersen (Ed.), Clinical behavior therapy: adults and children. New York: John Wiley \& Sons.

\section{Published Abstracts (arranged chronologically)}

McNeil, D. W., Frere, C. L., Crout, R. J., Yorty, J. S., Sorrell, J. T., \& Vowles, K. E. (2000, January). Audiovisual distraction effects on physiological responding during dental prophylaxis. Journal of Dental Research, 79, 289. [Abstract]

\section{Manuscripts - in Progress}

Vowles, K. E., \& Gross, R. T. (in progress). Work-related beliefs about injury and actual work capability in individuals with chronic pain.

Vowles, K. E., McNeil, D. W., \& Sorrell, J. T. (in progress). Fear and pain: Competing or synergistic states?

Larkin, K. \& Vowles, K. E. (in progress). Factors predicting treatment outcome to anger management training with mild essential hypertensive patients.

McNeil, D. W., Vowles, K.E., \& Sorrell, J.T. (in progress). Comparisons of social phobia, social phobia subtypes, and avoidant personality disorder: Key similarities and differences.

\section{Conference Presentations and Convention Proceedings \\ Regional, National, and International \\ (arranged chronologically)}

Vowles, K. E., \& Gross, R. T. (submitted). Work-related beliefs about injury: Mediators of functional capacity in individuals with chronic pain? Submitted for poster presentation at the 2002 meeting of the Amercian Pain Soceity, Baltimore, MA.

Vowles, K. E., O'Connell, C. E., Larkin, K. T., \& Zayfert, C. (submitted). Correlates of adherence in anger management training with essential hypertensives: Is treatment adherence related to behavioral and blood pressure changes? Submitted for poster or paper presentation at the 2002 meeting of the Society of Behavioral Medicine, Washington, D.C.

Vowles, K. E., Sorrell, J. T., McNeil, D. W., Lawrence, S. M., \& Rice, E. (submitted). Is fear painful? An experimental investigation into the relation between fear and pain. Poster submitted for presentation at the 2002 meeting of the Society of Behavioral Medicine, Washington, D.C. 
Sorrell, J. T., Vowles, K. E., Lawrence, S. M., \& McNeil, D. W. (submitted). Fear of pain in dentistry: current status and implications for treatment adherence. Submitted for paper presentation at the 2002 meeting of the Society of Behavioral Medicine, Washington, D.C.

Feldner, M. T., Zvolensky, M. J., Eifert, G. H., Spira, A. P., \& Vowles, K. E. (2001, November). An experimental investigation of experiential avoidance of a carbon dioxide-enriched air biological challenge. Poster presented at the meeting of the Association for the Advancement of Behavior Therapy, Philadelphia, PA.

Kennedy, S. G., McNeil, D. W, Hursey, K. G., Vowles, K. E., Sorrell, J. T., Lawrence, S. M., Patthoff, E. B., Whipkey, D. T., Broadman, L. M., Vaglienti, R. M., \& Huber, S. J. (2001, November). Development of a short form of the fear of pain questionnaire. Poster presented at the meeting of the Association for the Advancement of Behavior Therapy, Philadelphia, PA.

McNeil, D. W., Cohen, L. L., Crout, R. J., Berk, N. W., Weyant, R. J., Lawrence, S. M., Davis, B. A., Patthoff, E. B., Vowles, K. E., Sorrell, J. T., \& Tarter, R. E. (2001, November). Dental fear differences in appalachian children and their parents. Poster presented at the meeting of the Association for the Advancement of Behavior Therapy, Philadelphia, PA.

Sorrell, J. T., Vowles, K. E., McNeil, D. W., \& Lawrence, S. M. (2001, October). The role of predictability and controllability in pain and fear reduction during dental procedures. Poster presented at the West Virginia Psychological Association Fall Conference, Morgantown, WV.

Vowles, K. E., McNeil, D. W., Sorrell, J. T., McKee, D. R., Zvolensky, M. J., Graves, R. W, Weaver, B. R., Riel, J., \& Lawrence, S. M. (2001, March). Relation among fear, anxiety, and appointment adherence in oral surgery patients. Poster presented at the meeting of the Society of Behavioral Medicine, Seattle, WA.

Sorrell, J. T., McNeil, D. W., Vowles, K. E., Broadman, L. M., Hursey, K. G., Huber, S. J., Vaglienti, R. M., \& Kennedy, S. G. (2001, March). Effects of pain and fear stimulus intensity on pain responding in chronic pain patients. Poster presented at the meeting of the Society of Behavioral Medicine, Seattle, WA.

Sorrell, J. T., McNeil, D. W., Vowles, K. E., Broadman, L. M., Hursey, K. G., Huber, S. J., Vaglienti, R. M., \& Kennedy, S. G. (2000, November). Avoidance and escape behavior in laboratory-based pain induction in chronic pain patients. Poster presented at the meeting of the Association for the Advancement of Behavior Therapy, New Orleans, LA. [This poster also was presented in the February 2001 American Association for Dental Research poster session, Morgantown, WV.]

McNeil, D. W., Frere, C. L., Crout, R. J., Yorty, J. S., Sorrell, J. T., \& Vowles, K. E. (2000, April). Audiovisual distraction effects on physiological responding during dental prophylaxis. Poster presented at the International Association of Dental Research, Washington, DC. [This poster also was presented in the February 2000 American Association for Dental Research poster session, Morgantown, WV.]

Sorrell, J. T., McNeil, D. W., Vowles, K. E., Broadman, L. M., Hursey, K. G., Huber, S. J., Vaglienti, R. M., \& Kennedy, S. G. (2000, April). Effects of fear and pressure stimulation intensity on pain responding in chronic pain patients. Poster presented at the Eberly College of Arts and Sciences Student Research Spring Symposium, Morgantown, WV.

Sorrell, J. T., McNeil, D. W., Vowles, K. E., Broadman, L. M., Hursey, K. G., Huber, S. J., Vaglienti, R. M., \& Kennedy, S. G. (2000, March). Effects of fear and pressure stimulation intensity on pain responding in chronic pain patients. Poster presented at the West Virginia Psychological Association 
Spring Event \& Poster Session, Davis, WV. Received first place poster award.

Sorrell, J. T., McNeil, D. W., Vowles, K. E., Broadman, L. M., Hursey, K. G., Huber, S. J., Vaglienti, R. M., \& Kennedy, S. G. (2000, March). Effects of fear and pressure stimulation intensity on pain responding in chronic pain patients. Poster presented at the First Annual Sigma Xi Graduate Student Research Symposium, Morgantown, WV. Received third place poster award in the Behavioral and Social Sciences Division.

McNeil, D. W., Sorrell, J. T., \& Vowles, K. E. (1999, September). Interdisciplinary study of anxiety, stress, and pain. Poster presented at the Research Horizons in the $21^{\text {st }}$ Century Workshop of the Eberly College of Arts and Sciences, West Virginia University, Morgantown, WV.

\section{Teaching Experience}

Instructor (Fall 2001)

PSYC 253F - Health Psychology

Undergraduate Course

West Virginia University

Instructor (Fall 2000-Spring 2001)

PSYC 101 - Introduction to Psychology

Undergraduate Course

West Virginia University

Teaching Assistant (Fall 2000)

PSYC 379 - Introduction to Clinical Psychology

West Virginia University

\section{Professional Experience and Appointments}

Ad Hoc Co-Reviewer (2000)

Clinical Psychology: Science and Practice

Research Associate (2000 - Present)

West Virginia University

Department of Family Medicine

Morgantown, West Virginia

Graduate Student Therapist (2000 - 2001)

Behavioral Medicine Clinical Team

Quin Curtis Center for Psychological Service, Training, and Research,

Department of Psychology

West Virginia University

Morgantown, West Virginia

Responsible for assessment and treatment of individuals with a variety of presenting problems relevant to medical diseases. Received both individual and group supervision.

Research Associate (2000 - Present)

Behavioral Medicine Laboratory

West Virginia University

Department of Psychology

Morgantown, West Virginia 
Graduate Student Therapist (2000)

Department of Family Medicine

Robert C. Byrd Health Sciences Center

West Virginia University

Morgantown, West Virginia

Responsible for assessment and treatment of individuals presenting with a variety of problems to a general medical clinic. Received individual supervision.

Ad Hoc Co-Reviewer (2000)

Psychophysiology

Graduate Student Therapist (1999 2001)

Anxiety and Pain Clinical Team

Quin Curtis Center for Psychological Service, Training, and Research,

Department of Psychology

West Virginia University

Morgantown, West Virginia

Responsible for assessment and treatment of individuals with a variety of presenting problems. Received both individual and group supervision.

Research Associate (1999 - Present)

Anxiety, Psychophysiology, and Pain Research Laboratory

West Virginia University

Department of Psychology

Morgantown, West Virginia

Conducted applied and laboratory research on pain and anxiety, as well as their interaction. Participated in the supervision of three to four undergraduate research assistants.

Ad Hoc Co-Reviewer (1999)

Journal of Abnormal Psychology

Mental Health Worker

Behavioral Health Inpatient Unit

Boulder Community Hospital

Boulder, Colorado

Responsible for mileau management on a 18 bed inpatient unit. Conducted intake interviews, suicide and substance abuse assessments, and group instruction in relaxation techniques.

Biofeedback Technician / Relaxation Instructor (1998 - 1999)

Anesthesiology and Pain Management

University of Colorado Health Sciences Center

Denver, Colorado

Instructed individuals with chronic pain in a variety of relaxation techniques. Utilized biofeedback

equipment and software during relaxation instruction to enhance outcome.

Research Assistant (1998 - 1999)

Anesthesiology and Pain Management

University of Colorado Health Sciences Center

Denver, Colorado

Conducted applied research with individuals diagnosed with a chronic pain condition. Assisted in research

design and formulation, data entry and coding, and statistical analyses.

Mental Health Worker 
Mental Health Center of Boulder County

Boulder, Colorado

Responsible for Mileau Management in a clubhouse-type setting for individuals diagnosed with a variety of mental illnesses. Assisted in providing opportunities for social interactions and activities.

Volunteer

Mental Health Center of Boulder County

Boulder, Colorado

Assisted an individual with a 25 year history of severe mental illness in maintaining a semi-independent lifestyle. Provided opportunities for social interaction and activities. 


\section{References}

J. Kenneth Arnette, Ph.D., Ph.D.

Assistant Professor

Department of Psychology, MS 94

Eastern Washington University

Cheney, WA 99004

Daniel W. McNeil, Ph.D.

Associate Professor

310 Oglebay Hall

Department of Psychology

West Virginia University

P.O. Box 6040

Morgantown, WV 26506-6040

Brent Van Dorsten, Ph.D.

Assistant Professor

Campus Box C279

East Pavilion, Room 059

S/M Rehabilitation Medicine - Rehabilitation

University of Colorado

Denver, CO 89219 